\title{
Environmental Remediation of Antineoplastic Drugs: Present Status, Challenges, and Future Directions
}

\author{
Abhilash Kumar Tripathi ${ }^{1}$, Aditi David ${ }^{1}$, Tanvi Govil ${ }^{1,2}$, Shailabh Rauniyar ${ }^{1}$, \\ Navanietha Krishnaraj Rathinam ${ }^{1,3}$, Kian Mau Goh ${ }^{4}$ (D) and Rajesh Kumar Sani ${ }^{1,2,3, *(D)}$ \\ 1 Department of Chemical and Biological Engineering, South Dakota School of Mines and Technology, \\ Rapid City, SD 57701, USA; abhilashkumar.tripathi@mines.sdsmt.edu (A.K.T.); \\ aditi.david@mines.sdsmt.edu (A.D.); tanvi.govil@mines.sdsmt.edu (T.G.); \\ shailabh.rauniyar@mines.sdsmt.edu (S.R.); Navanietha.Rathinam@sdsmt.edu (N.K.R.) \\ 2 Composite and Nanocomposite Advanced Manufacturing Centre-Biomaterials, Rapid City, SD 57701, USA \\ 3 BuG ReMeDEE Consortium, South Dakota School of Mines and Technology, Rapid City, SD 57701, USA \\ 4 Faculty of Science, Universiti Teknologi Malaysia, Johor 81310, Malaysia; gohkianmau@utm.my \\ * Correspondence: Rajesh.sani@sdsmt.edu; Tel.: +1-605-394-1240
}

Received: 27 May 2020; Accepted: 20 June 2020; Published: 27 June 2020

\begin{abstract}
The global burden of cancer is on the rise, and as a result, the number of therapeutics administered for chemotherapy is increasing. The occupational exposure, recalcitrant nature and ecotoxicological toxicity of these therapeutics, referred to as antineoplastic (ANP) drugs, have raised concerns about their safe remediation. This review provides an overview of the environmental source of ANPs agents, with emphasis on the currently used remediation approaches. Outpatient excreta, hospital effluents, and waste from pharmaceutical industries are the primary source of ANP waste. The current review describes various biotic and abiotic methods used in the remediation of ANP drugs in the environment. Abiotic methods often generate transformation products (TPs) of unknown toxicity. In this light, obtaining data on the environmental toxicity of ANPs and its TPs is crucial to determine their toxic effect on the ecosystem. We also discuss the biodegradation of ANP drugs using monoculture of fungal and bacterial species, and microbial consortia in sewage treatment plants. The current review effort further explores a safe and sustainable approach for ANP waste treatment to replace existing chemical and oxidation intensive treatment approaches. To conclude, we assess the possibility of integrating biotic and abiotic methods of ANP drug degradation.
\end{abstract}

Keywords: antineoplastic drug; environment; toxicity; remediation; biodegradation

\section{Introduction}

Last few decades have experienced rising concerns over the release of pharmaceutical drugs into the environment. Though pharmaceutical compounds have targeted effects on the human body, the knowledge about the direct impact of their transformation products (TPs) and metabolites on other organisms and indirect effects on human health is scarce. Antineoplastic (ANP) drugs (also known as anticancer or cytostatic) are a specific group of pharmaceutical compounds which prevent, inhibit, or terminate the development of cancer. However, due to their non-specific mode of action, affecting both cancerous and healthy cells, ANP drugs exhibit cytotoxic, genotoxic, mutagenic, carcinogenic and teratogenic effects in all eukaryotic cells [1-3]. Nevertheless, due to their low environmental concentrations (10-100 $\mathrm{ng} / \mathrm{L}$ or below), there is not enough evidence to accurately assess whether or not ANPs have an impact on the environment [4]. However, since they are designed to disrupt or prevent cellular proliferation, usually by interfering in DNA synthesis, their fate and transport in the environment should be explored. 
The World Health Organization estimated the global burden of cancer at 18.1 million new cases and 9.6 million deaths in 2018 [5]. As per an evaluation by the American Cancer Society, 1,806,590 new cancer cases and 606,520 cancer deaths are projected to occur in the United States by 2020 [6]. In compliance with this trend of increasing cancer prevalence, new ANP drugs are also being designed, tested, and manufactured at an increasing rate [7]. Over the past few years, 70 new ANP drugs have been released to treat 20 variants of tumors (cancerous growths), the number of ANP drugs has expanded by more than $60 \%$ [8]. More than 500 companies are currently pursuing ANP drug development, with 300 companies having cancer drugs under clinical development stages [8]. Figure 1a,b shows the total number of ANP drugs approved in USA and EU, and total ANP molecules under different phases of development, respectively. In 10 years from 2010 to 2020, ANP drug production is expected to double [9]. The production of novel ANP drugs has varied greatly across countries over the years. For example, in 2004, Canada and Australia consistently produced a higher volume of ANP drugs (51 and 39 for Australia and Canada, respectively) whereas United States and Germany produced significantly lower volume (29 and 17 for Germany and United States, respectively). On the other hand, in 2014, United States and Germany produced higher volume of novel ANP drugs [10]. A comparative global heatmap of some prominent ANP drug producing countries in 2004 and 2014 is shown in Figure 1c. The raw data of Figure 1c is given in Table S1 of Supplementary Information. In addition to the production, it is also crucial to highlight the sites where ANPs are mostly released into the environment. However, there is not enough data to categorize sites in terms of ANP emission into the environment. The number of publications on occurrence of ANP compounds in environment is scarce, and most of studies to date are almost exclusively focused on Europe [11]. Nevertheless, the number of cancer cases in different countries can be a governing factor that dictates the introduction of these compounds in the environment. The country with highest number of cases will consume the most ANP drugs and hence there will be a greater probability of introduction of these compounds into the environment. The global heatmap of the number of cancer cases in different countries per 100,000 people is given in Figure 1d. The raw data was obtained from the GLOBOCAN online database [12], and is provided in Table S2 of the Supplementary Information.

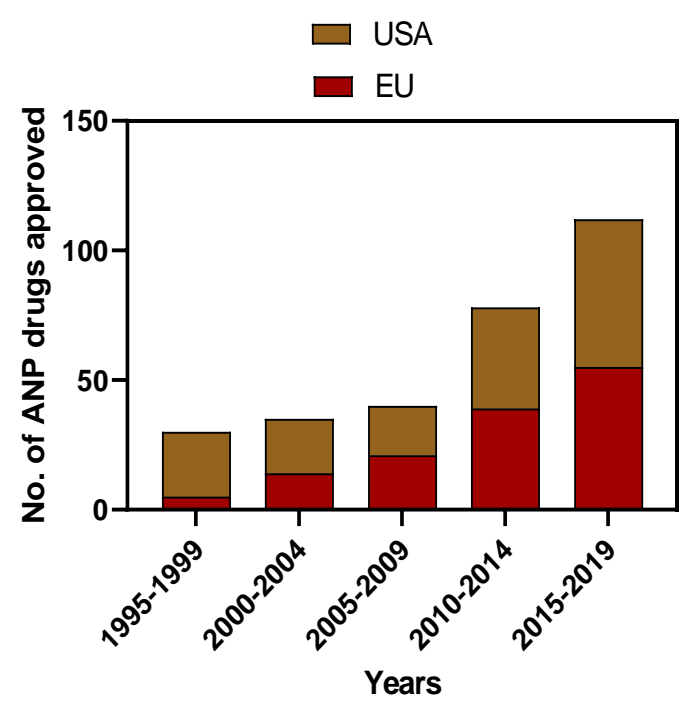

(a)

Figure 1. Cont. 


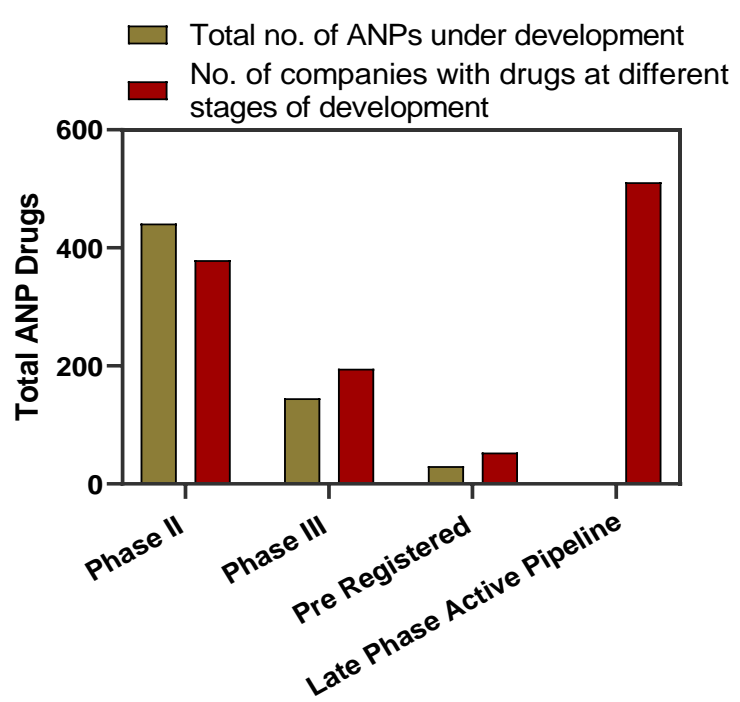

(b)

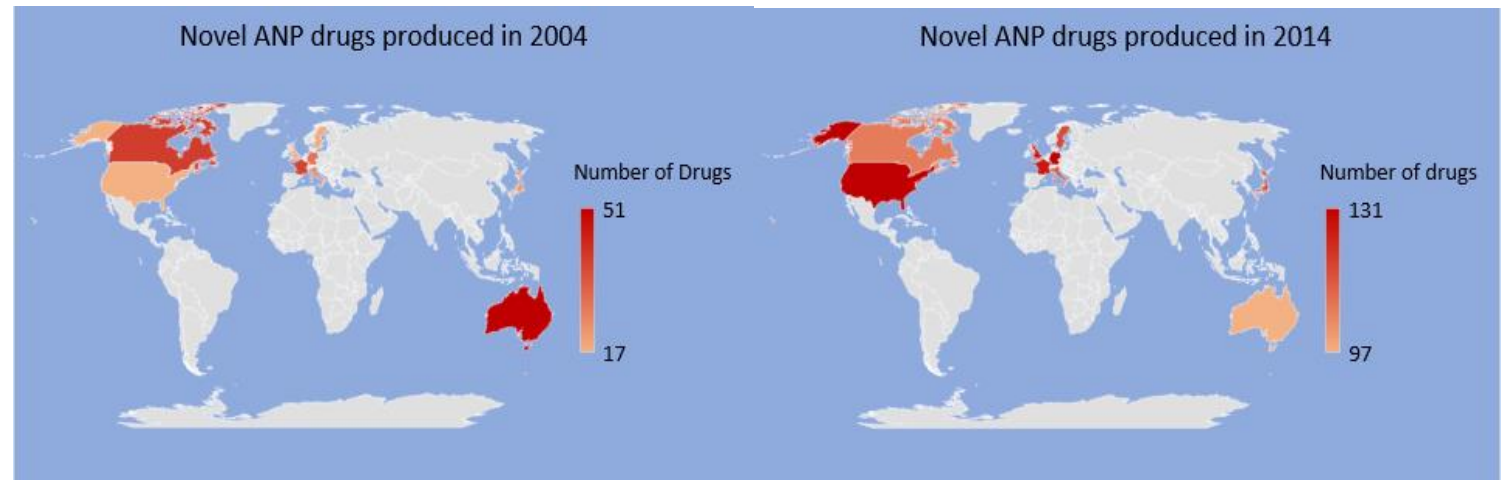

(c)

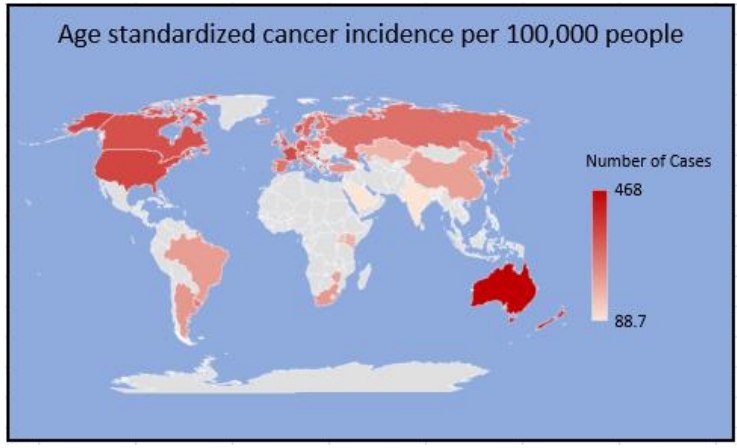

(d)

Figure 1. (a) Number of antineoplastic (ANP) drugs approved between 1995 and 2019 in USA and European Union (EU) [7,13-15]; (b) The Global Late Phase Oncology Pipeline in 2015 [8]; (c) comparative global heatmap of ANP drug produced in some select countries in 2004 and 2014 [10]; (d) age standardized cancer incidence in select countries in 2018 [12]. (Phase II and Phase III refers to ANP drugs that are at second and third phase of clinical trials, respectively).

ANP drugs are categorized into different groups based on the organ or system on which they act and their therapeutic, pharmacological, and chemical properties [16]. These different categories of ANP drugs differ in their chemical structures and physicochemical properties. The physicochemical properties play an indispensable role in the potential fate of these drugs in the environment [17]. Building a physicochemical profile of ANPs will allow for their partitioning, and help us study the 
fate of ANPs within aquatic and terrestrial ecosystems [18]. In total, 102 active antineoplastic drugs have been identified which are environmentally relevant [19]. Section 2 of this review describes the parameters that determine the fate and distribution of ANPs in the environment.

Though used in minimal quantity, ANP drugs persist in the environment [19] and can be harmful even if present under low concentrations [20,21]. All ANP compounds are potent immunosuppressive agents and have a high pharmacological potency that is fatal to aquatic and terrestrial organisms [22]. Significant disadvantages and environmental concerns associated with the usage of ANP drugs include the following: (i) inevitable contamination of natural ecosystems (terrestrial and aquatic) by the drugs themselves and their potentially toxic transformation products (TPs); (ii) scarcity of complete and coherent knowledge on the environmental fate of these drugs, its human metabolites, or TPs; (iii) their biomagnification at various trophic levels which can have adverse effects on the flora and fauna of the contaminated ecosystems.

The aforesaid environmental concerns have made it imperative to develop a safe, economical, and environmentally friendly process to remediate residual ANP drugs in the ecosystem. To date, limited studies have been successful in using a single microbial system or microbial consortia for the complete or partial elimination of ANP wastes [23-26]. The integration of microbial bioremediation systems with abiotic remediation techniques can be beneficial as it will decrease the requirements of harsh chemicals and may also reduce the generation of toxic degradation products [27]. This review presents a case for integrating abiotic and biotic modes of ANP degradation. With our decade-long continuous exploration in the field of extremophilic bioprocessing and bioremediation [28-34], we have identified the scope of thermophilic microbes and thermophilic bioprocessing towards developing sustainable and environment friendly methods of ANP waste degradation.

The primary objectives of this review effort are to (i) outline the parameters that affect the circulation of ANP drugs in an environment; (ii) provide a brief overview of the source, types, and concentration of ANPs in the environment; (iv) compare and contrast the Environmental Risk Assessment (ERA) strategies being implemented in different regions; (iii) compile the information on existing biotic and abiotic methods of remediation of ANP drugs; (iv) discuss the possibility of designing a more energy efficient remediation method through integration of biotic and abiotic methods of treatment.

\section{Parameters Determining the Fate and Distribution of ANPs}

The decomposition or deactivation of ANP drugs in the waste treatment plants and environment is greatly influenced by the individual physicochemical properties of ANPs and its TPs [4]. The physicochemical properties of some common ANP drugs are listed in Table 1, that include octanol-water partition coefficient/hydrophobicity $\left(\mathrm{K}_{\mathrm{ow}}\right)$, dissociation constant $\left(\mathrm{pK}_{\mathrm{a}}\right)$, solubility, toxicity, biological half-life, bioconcentration factor $(\mathrm{BCF})$, and organic carbon partition coefficient $\left(\mathrm{K}_{\mathrm{oc}}\right)$. 
Table 1. Physico-chemical properties and ecotoxicological data of common ANP drugs.

\begin{tabular}{|c|c|c|c|c|c|c|c|}
\hline ANP Drug & Chemical Structure & $\log K_{\text {ow }}$ & $p K a a^{f}$ & $\begin{array}{c}\text { Solubility in } \\
\left.\text { Water (at } 25^{\circ} \mathrm{C}\right)\end{array}$ & $\begin{array}{l}\text { Toxicity }\left(\mathrm{LD}_{50}{ }^{\mathrm{d}}\right. \\
\text { Value, Oral) }\end{array}$ & $\begin{array}{l}\text { Biological } \\
\text { Half-Life e }\end{array}$ & BCF \\
\hline 5-FU & & -0.89 & 8.02 & $11.1 \mathrm{~g} / \mathrm{L}$ & $230 \mathrm{mg} / \mathrm{kg}$ (mice) & $10-20 \mathrm{~min}$ & 3 \\
\hline $\mathrm{CP}$ & & 0.63 & 2.84 & $10-50 \mathrm{~g} / \mathrm{L}$ & $\begin{array}{c}275 \text { to }>400 \mathrm{mg} / \mathrm{kg} \\
\text { (Rats) }\end{array}$ & $3-12 \mathrm{~h}$ & 2.1 \\
\hline DOX & & 1.27 & $\begin{array}{l}7.34\left(\mathrm{pKa}_{1}\right) \\
8.46\left(\mathrm{pKa}_{2}\right) \\
9.46\left(\mathrm{pKa}_{3}\right)\end{array}$ & $2.6 \mathrm{~g} / \mathrm{L}$ & $16 \mathrm{mg} / \mathrm{kg}$ (rats) & $20-48 \mathrm{~h}$ & 1 \\
\hline TAM & & 6.30 & 8.87 & Insoluble & $4100 \mathrm{mg} / \mathrm{kg}$ (rats) ${ }^{\mathrm{a}}$ & 5-7 days & 827 \\
\hline
\end{tabular}


Table 1. Cont.

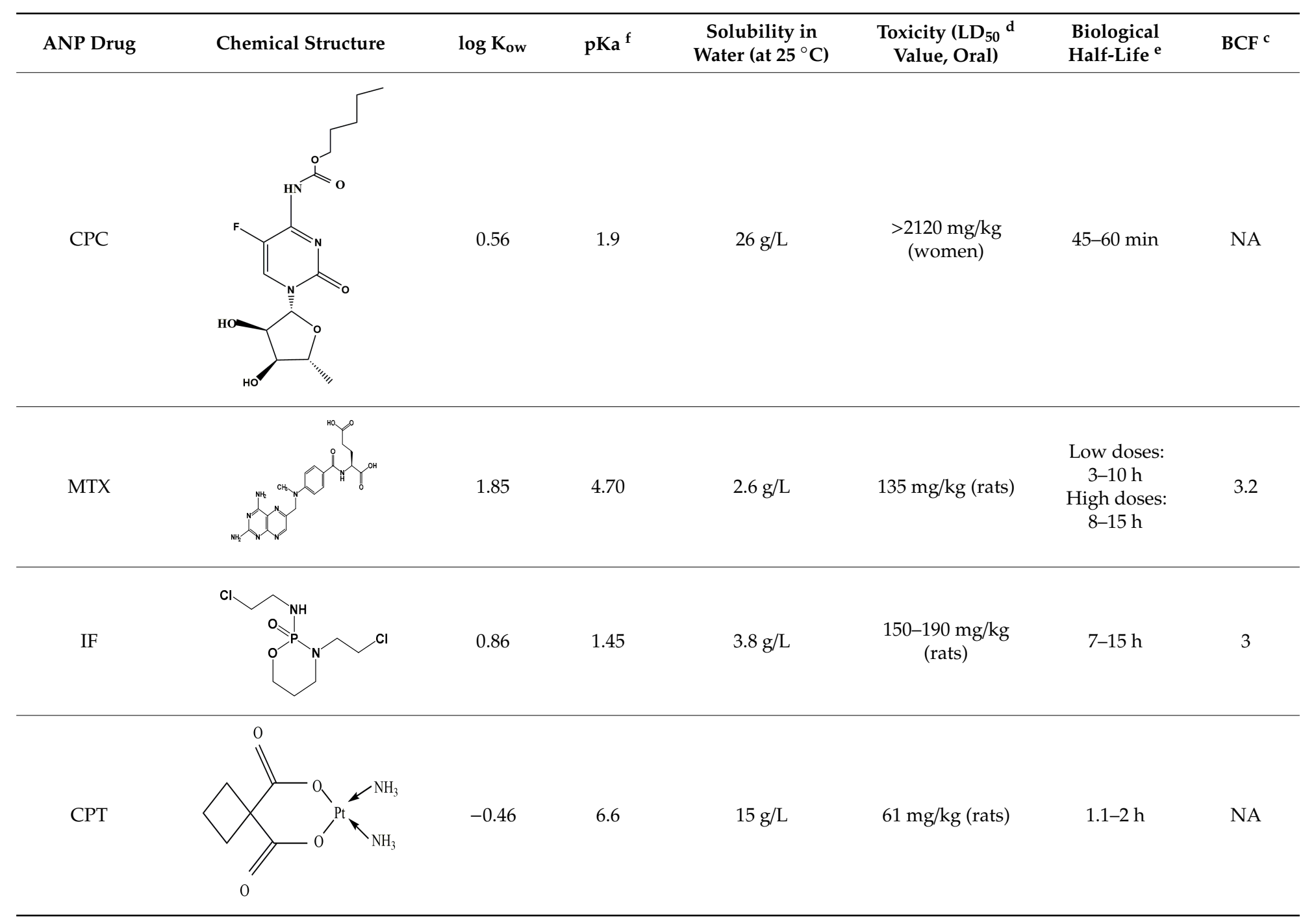


Table 1. Cont

\begin{tabular}{|c|c|c|c|c|c|c|c|}
\hline ANP Drug & Chemical Structure & $\log K_{\text {ow }}$ & $\mathrm{pKa}^{\mathrm{f}}$ & $\begin{array}{c}\text { Solubility in } \\
\text { Water (at } 25^{\circ} \mathrm{C} \text { ) }\end{array}$ & $\begin{array}{c}\text { Toxicity }\left(\mathrm{LD}_{50} \mathrm{~d}\right. \\
\text { Value, Oral) }\end{array}$ & $\begin{array}{l}\text { Biological } \\
\text { Half-Life }\end{array}$ & $\mathrm{BCF}^{\mathrm{c}}$ \\
\hline PEM & & 0.16 & $\begin{array}{l}3.6\left(\mathrm{pKa}_{1}\right) \\
4.4\left(\mathrm{pKa}_{2}\right)\end{array}$ & Insoluble & 1754 mg/kg (rats) & $3.5 \mathrm{~h}$ & 3.2 \\
\hline GEM & & -2.01 & 3.6 & $51.3 \mathrm{~g} / \mathrm{L}$ & $\begin{array}{c}500 \mathrm{mg} / \mathrm{kg} \text { (mice } \\
\text { and rats) }\end{array}$ & $\begin{array}{l}\text { Short infusions: } \\
\text { 42-94 min } \\
\text { Long infusions: } \\
\text { 245-638 min }\end{array}$ & 1 \\
\hline СТВ & & -2.46 & 4.22 & $17.6 \mathrm{~g} / \mathrm{L}$ & 3150 mg/kg (mice) & $10 \mathrm{~min}$ & 1 \\
\hline $\mathrm{AZT}$ & & 0.10 & 7.87 & Insoluble & 400 mg/kg (rats) & $12-15 \mathrm{~min}$ & NA \\
\hline
\end{tabular}


Table 1. Cont.

\begin{tabular}{|c|c|c|c|c|c|c|c|}
\hline ANP Drug & Chemical Structure & $\log K_{\text {ow }}$ & $\mathrm{pKa}^{\mathrm{f}}$ & $\begin{array}{c}\text { Solubility in } \\
\left.\text { Water (at } 25^{\circ} \mathrm{C}\right)\end{array}$ & $\begin{array}{l}\text { Toxicity }\left(\mathrm{LD}_{50}{ }^{\mathrm{d}}\right. \\
\text { Value, Oral) }\end{array}$ & $\begin{array}{l}\text { Biological } \\
\text { Half-Life e }\end{array}$ & $\mathrm{BCF}^{\mathrm{c}}$ \\
\hline ETS & & 0.60 & 9.8 & $\begin{array}{l}\text { Sparingly soluble } \\
(0.08 \mathrm{~g} / \mathrm{L})\end{array}$ & 118 mg/kg (mice) & $4-11 \mathrm{~h}$ & 3 \\
\hline SFL & & -0.62 & 10.6 & $7.5 \mathrm{~g} / \mathrm{L}$ & 3700 mg/kg (mice) & $\begin{array}{l}\text { Dependent on } \\
\text { renal function }\end{array}$ & 0.2 \\
\hline DAU & & 1.83 & 7.85 & $30 \mathrm{~g} / \mathrm{L}$ & 1737 mg/kg (mice) & $36 \pm 13 h$ & 110 \\
\hline
\end{tabular}

Notes: 5-FU: 5-Fluorouracil; CP: Cyclophosphamide; DOX: Doxorubicin; TAM: Tamoxifen; CIP: Ciprofloxacin; CPC: Capecitabine; MTX: Methotrexate; IF: Ifosfamide; CPT: Carboplatin; PEM: Pemetrexed; GEM: Gemcitabine; CTB: Cytarabine; AZT: Azathioprine; ETS: Etoposide; SFL: Sulfanilamide; DAU: Daunorubicin. Physico-chemical and toxicity value data sources: HSDB-Hazardous Substances Data Bank (https://toxnet.nlm.nih.gov/cgi-bin/sis/htmlgen?HSDB), PubChem (https://pubchem.ncbi.nlm.nih.gov/), toxicity value data sources: HSDB-Hazardous Substances Data Bank (https://toxnet.nlm.nih.gov/cgi-bin/sis/htmlgen?HSDB), PubChem (https://pubchem.ncbi.nlm.nih.gov/),
ChemSpider (http://www.chemspider.com/). N.A. no data available. a Cayman Chemical-MSDS of Tamoxifen (https://www.caymanchem.com/msdss/13258m.pdf). b Pfizer-MSDS of Ciprofloxacin (http://www.pfizer.com/files/products/material_safety_data/PZ01031.pdf). ${ }^{\mathrm{c}}$ BCF stands for bioconcentration factor which indicates biomagnification (BMG) risk (low BMG risk (<100); moderate BMG risk (100-1000)); very high BMG risk $(>1000)$ [21,35]. ${ }^{d}$ LD50 is the dosage of a given drug that kills 50\% of the test population. e Biological half-life is the time required for half of the total drug in a biological system to be degraded by biological process when the rate of removal is nearly exponential (https://medical-dictionary.thefreedictionary.com/biological + half-life). ${ }^{\mathrm{f}} \mathrm{pKa}$ is the acid-base dissociation constant (pKa affects ionization of weakly basic and weakly acidic ANPs. The ionization of basic drugs for instance is suppressed at $\mathrm{pH}$ above their $\mathrm{pKa}$ and is enhanced at a $\mathrm{pH}$ below their $\mathrm{pKa}$ [36]; $\mathrm{pKa}_{1}$, $\mathrm{pKa}_{2}$, and $\mathrm{pKa} 3$ are the dissociation constants for first, second, and third ionization, respectively). 
Sorption (absorption and adsorption) which is influenced by these physico-chemical parameters is the key unit operation in remediation of ANPs [37,38]. One of the key factors that determines the fate of ANPs in effluents flown from the treatment facilities is the magnitude of ANPs sorption onto organic matter [39]. In addition, the chemical structure of the ANPs also determines the mechanism and effectiveness of sorption [4]. Sorption of a chemical/organic compound to an organic matter is determined using the octanol/water partition coefficient $\left(\mathrm{K}_{\mathrm{ow}}\right)$ and organic carbon normalized sorption coefficient $\left(K_{o c}\right)$ which are derived from n-octanol/water distribution coefficient $\left(D_{o w}\right)$ and the solid-water distribution coefficient $\left(\mathrm{K}_{\mathrm{d}}\right)$, respectively. $\mathrm{K}_{\mathrm{d}}$ value dictates both adsorption and absorption of the chemical compound to natural organic matter [39]. The dissemination of a chemical/organic compound between lipids and fats, sorption to biomass and distribution among environmental compartments is indicated by $D_{o w}$. However, $D_{\text {ow }}$ cannot be applied to organic compounds with multiple functional groups because such compounds rapidly ionize at environmental $\mathrm{pH}$ levels. $\mathrm{D}_{\mathrm{ow}}$ is therefore corrected for $\mathrm{K}_{\mathrm{ow}}$ which considers concentration of non-ionized species only. For undissociated compounds, $\log \mathrm{D}_{\mathrm{ow}}$ is approximately equal to $\log \mathrm{K}_{\mathrm{ow}}$. In general, $\log \mathrm{K}_{\mathrm{ow}}<1$ indicates that a chemical compound is highly mobile in aquatic and is unlikely to sorb onto organic matter (with the exception of IB $\left.\left(\log \mathrm{K}_{\mathrm{ow}}=3\right)\right)$ that remains in the water phase and is less likely to undergo sorption. On the other hand, $\log \mathrm{K}_{\mathrm{ow}} \geq 3$ is indicative of a hydrophobic compound that can undergo rapid sorption. Based on $\log \mathrm{K}_{\mathrm{ow}}$, it is possible to separate a mixture of ANPs and investigate potential toxicity of the ANPs [22]. From Figure 2 and Table 1, we can see that many ANPs are highly polar with $\log \mathrm{K}_{\mathrm{ow}}$ values $<1$. This suggests that they will mostly be distributed in the water phase. In fact, in many studies, both cyclophosphamide $\left(\mathrm{CP}, \log \mathrm{K}_{\mathrm{ow}}=0.63\right)$, and ifosfamide $\left(\mathrm{IF}, \log \mathrm{K}_{\mathrm{ow}}=0.86\right)$, were detected at concentration $(w / w)$ of $<2 \times 10^{-5} \mathrm{mg} / \mathrm{gram}$ of sewage sludge, where their concentrations per liter of the sewage treatment plant influent were $10^{2}-10^{3}$ times higher $[21,40,41]$. Therefore ANPs with $\log \mathrm{K}_{\mathrm{ow}}$ values $<1$ are unlikely to be eliminated by adsorption onto sewage sludge, and if they are not biodegraded, they will pass onto surface waters [25,42]. The $\log \mathrm{K}_{\mathrm{ow}}$ values, when plotted with half-life of the ANPs (Figure 2), shows that the drugs with higher biological half-life possesses higher hydrophobicity $\left(\log \mathrm{K}_{\mathrm{ow}}>2\right)$. Though, there are some outliers that do not fit the curve (Figure 2), more than $80 \%$ of the data demonstrates the expected trend. For hydrophobic ANPs, adsorption to biomass plays an important role in their elimination process and as such hydrophobic ANPs can be removed by using an adsorption based remediation method such as powered activated carbon [43].
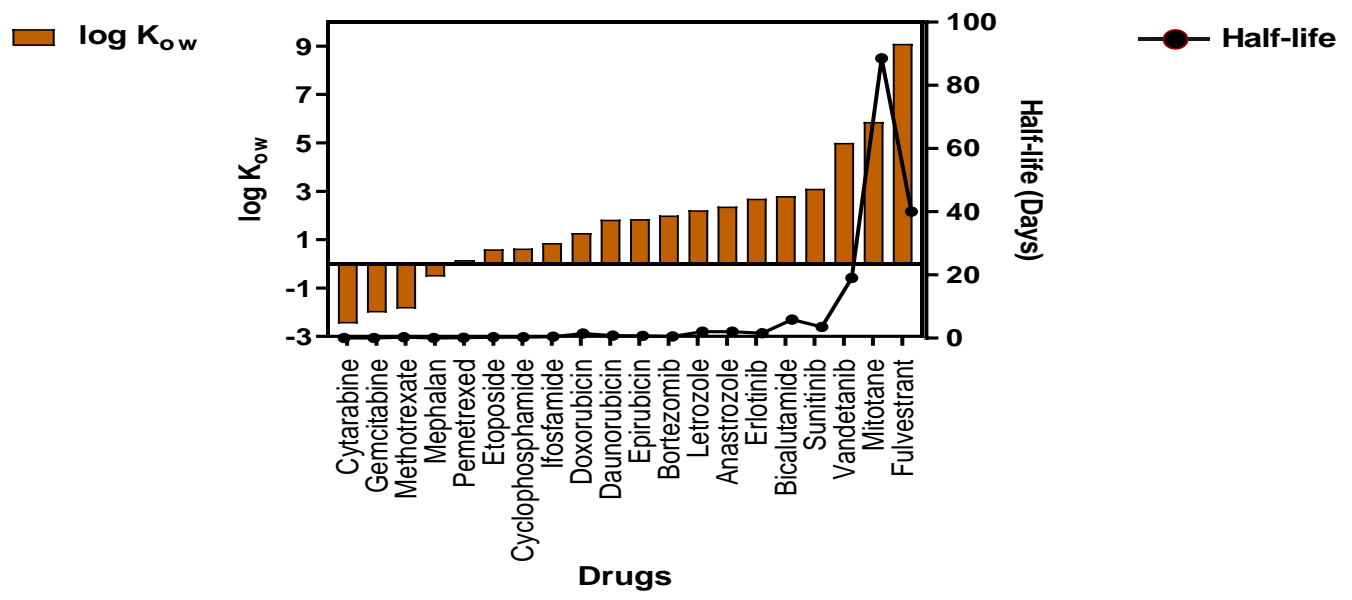

Figure 2. Plot indicating relationship between hydrophobicity and half-life of common ANP drugs. Drugs list obtained from NIOSH List of Antineoplastic and Other Hazardous Drugs in Healthcare Settings, 2016 (https://www.cdc.gov/niosh/docs/2016\$-\$161/pdfs/2016-161.pdf?id=10.26616/ NIOSHPUB2016161). $\mathrm{K}_{\mathrm{ow}}$ and half-life values were obtained from PubChem (https://pubchem.ncbi. nlm.nih.gov/) and DrugBank (https://www.drugbank.ca/). 
The acid-base dissociation constant (pKa) is a key physicochemical parameter that describes the extent to which a compound would dissociate at a particular $\mathrm{pH}$. For example, methotrexate (MTX) has a relatively low dissociation constant, and therefore it is more likely to be dissociated in the aquatic ecosystem. MTX therefore has high mobility in the aquatic environment because of its high polarity [22]. The typical range of pKa values that a compound may have is related to the nature and frequency of occurrence of the functional groups that are commonly observed in pharmaceuticals including ANPs. Another important parameter is solubility which varies widely amongst the different classes of ANP drugs. It varies from 0 for some plant alkaloids class of ANPs to as high as $10^{4}$ and $10^{5} \mathrm{mg} / \mathrm{L}$ for ANP drugs such as capecitabine (CPC), cytarabine (CTB), cyclophosphamide (CP), and 5-fluorouracil (5-FU) as mentioned in Table 1. In fact, due to the combination of low $\log \mathrm{K}_{\mathrm{ow}}$ (hydrophilic) and high water solubility, some ANP drugs such as cisplatin (CPT), carboplatin (CBT), and oxaliplatin (OXT) become highly mobile in the aquatic environment [44]. In the same light, it is also important to mention bioconcentration factor (BCF), which indicates the biomagnification risk. Most cytostatic drugs have BCF between 1 and 4. However, for some other ANPs such as tamoxifen (TAM) and bicalutamide (BLT) BCF is 827, while lapatinib (LTB) has BCF of 2535, mitotane (MTN) 7649, and estramustine (ERT) 13,783 , which is indicative of an extremely high potential for bioconcentration in aquatic organisms [43]. It could thus be potentially dangerous to humans as well. These physico-chemical parameters are therefore important factors that should be taken into consideration before designing environmental risk assessment programs, and biotic and abiotic degradation strategies.

\section{Sources of ANPs in the Environment}

Since the very first detection of ANP drugs in the aquatic environment in 1985 [45], various studies have discovered different classes of ANP drugs in the aquatic environment, with negligible or almost unchanged structural conformation [46]. ANP agents are mostly introduced into the environment through the urine and feces of outpatients who consume the drug at home (oral chemotherapy), or patients who undergo chemotherapy at hospitals $[1,40]$. Particularly effluents from cancer hospitals or hospital wards specialized in oncology are the key emission source of ANP drugs in the aquatic environment $[47,48]$. In fact, excretions of patients undergoing chemotherapy at hospitals is the main source of introduction of ANP drugs in the environment [43]. The excretion route (feces or urine) is dependent on the type of drug administered. For example, $70 \%$ of bleomycin (in less than $2 \mathrm{~h}$ ) and $40 \%$ of doxorubicin (in 5 days) is excreted in urine, and $50 \%$ of irinotecan (ITN) ( $48 \mathrm{~h}$ ) in feces [43]. A few more ANP drugs such as MTX and pemetrexed (PEM) have shown high urinary excretion rates $(\approx 90 \%)$. MTX and PEM are mainly excreted as human metabolites of the parent drug [21,49]. For example, the urinary excretion of $5-\mathrm{FU}$ is only about $15 \%$ as parent compound (5-FU), and $80 \%$ as its metabolite R-fluoro-alanine [50]. The excretion rate of ANP drugs varies with medication (duration of medication, formulation), mode of application (intradermal, intravenous, oral), and metabolic rates among treated patients. Figure 3 shows the possible routes for the introduction of pharmaceutical drugs into the environment. The occurrence and concentration of ANPs in effluents is also dependent on many factors, such as the number of patients, the physico-chemical nature of the drug used, dosing, excretion rates, methods of sampling, storage, and transport, as well as daily water consumption, which can significantly dilute the effluent and affect the detectability of ANP and its TPs [43]. ANPs through effluents can enter the aquatic environment unaltered or as TPs depending on the physicochemical characteristics discussed in Section 2. These drugs or their TPs can have detrimental effects on the environment, aquatic life, and human health [20]. Due to danger that these drugs pose, it is important to gather data on the usage of ANPs in a decentralized way because every patient and hospital do not use the same type ANP drugs. Such decentralized categorization of data would also help in designing efficient environmental risk assessment and remediation strategies. 


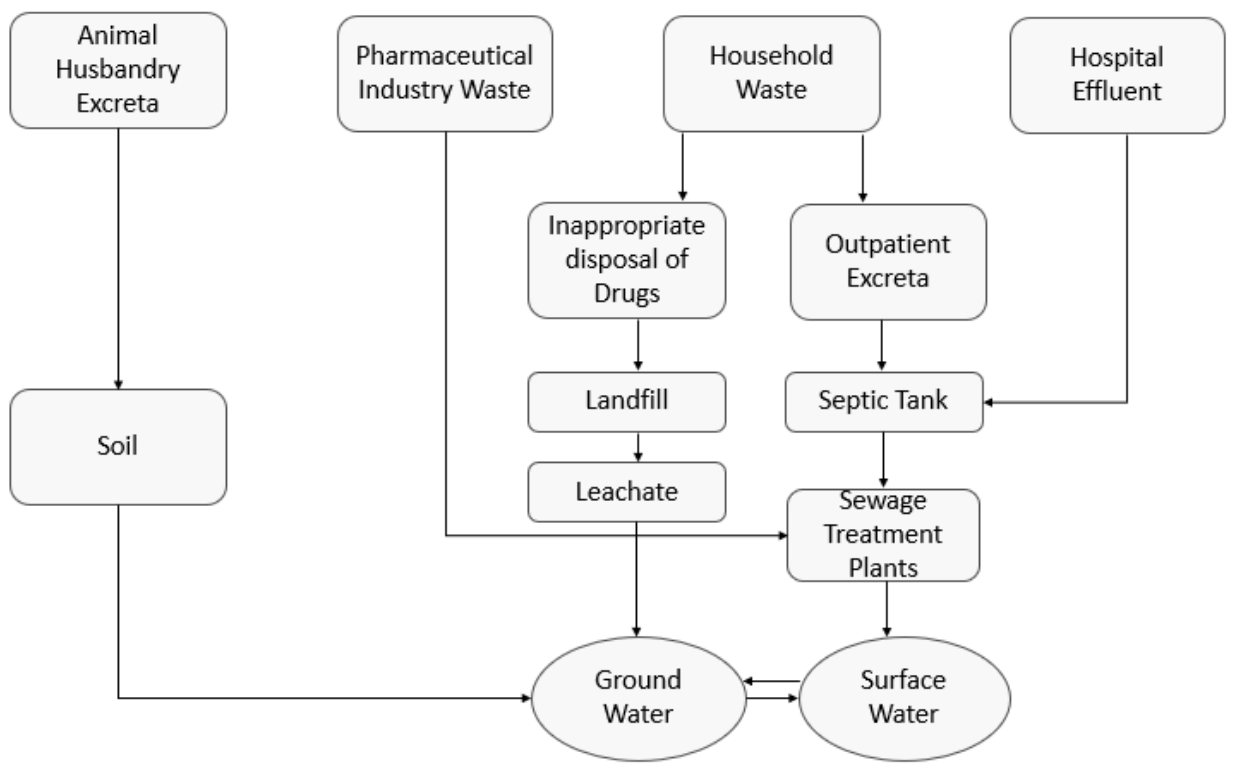

Figure 3. Sources for the introduction of ANP waste into the environment (modified from [51,52]).

\section{Environmental Risk Assessment (ERA) of ANPs}

Recent years have seen a sharp spike in the number of ANP drugs in the market which has promoted anticancer home treatments [40]. As a result, more ANPs are being increasingly reported in wastewater and natural water bodies $[17,20,53]$. Due to their increased accumulation and highly hazardous nature, it has become imperative to quantify the concentration of ANPs in the environment and carry out an environmental risk assessment (ERA). The ERA methodology varies in different regions of the world. The European medical agency (EMA) calculates the predicted environmental concentration (PEC) in addition to screening the persistence, bioaccumulation, and toxicity of the drug during phase I assessment [54,55]. The PEC value is calculated using the following Equation (1) [55].

$$
\mathrm{PEC}_{\mathrm{SW}}=\left(\mathrm{DOSE}_{\mathrm{AS}} \times \mathrm{F}_{\mathrm{PEN}}\right) /\left(\mathrm{WASTEW}_{\mathrm{INHAB}} \times \mathrm{DILUTION}\right)
$$

where, $\mathrm{PEC}_{\mathrm{SW}}$ predicted environmental concentration for surface water $(\mathrm{mg} / \mathrm{L})$; $\mathrm{DOSE}_{\mathrm{AS}}$ is the maximum daily dose of the active substance consumed per inhabitant (mg/inh.d); $F_{P E N}$ is the fraction

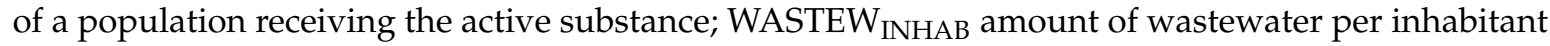
per day (L/inh.d); DILUTION is the dilution factor.

As per the EMA standard guidelines, if the $\mathrm{PEC}_{\mathrm{SW}}$ value is $<10 \mathrm{ng} / \mathrm{L}$, the pharmaceutical drug is unlikely to represent a risk to the environment [55]. Persistence, bioaccumulation, and other toxicity tests are not required for ANPs that fall under this category. Lipophilic ANPs ( $\left.\log \mathrm{K}_{\mathrm{ow}}>4.5\right)$ are directly moved to phase II because of their bioaccumulative nature. In contrast, the USA uses different ERA methodology where the drugs are first sorted based on its potency to enter the environment. Various tests such as the water solubility test, dissociation constant test, octanol/water partition coefficient $\left(\mathrm{K}_{\mathrm{ow}}\right)$ test, and vapor pressure is conducted on the sorted drugs. The environment introduction concentration (EIC) is then estimated using the following Equation (2) [55].

$$
\mathrm{EIC}_{\mathrm{AQ}}=\mathrm{A} \times \mathrm{B} \times \mathrm{C} \times \mathrm{D}
$$

where, EICAQ: expected introduction concentration of an active moiety into the aquatic environment (ppb); A: amount produced for direct use as active moiety (kg/year); B: inverse of liters per day entering the publicly owned treatment works, (POTWs) (day/L); C: conversion factor (year/365 day); $\mathrm{D}$ : conversion factor $(109 \mu \mathrm{g} / \mathrm{kg})$. If the $\mathrm{EIC}_{\mathrm{AQ}}<1000 \mathrm{ng} / \mathrm{L}$, the drug is excluded from further testing. $\mathrm{PEC}_{\mathrm{SW}}$ is generally lower than $\mathrm{EIC}_{\mathrm{AQ}}$ due to dilution factor. 
When compared to EU and USA, Canada's ERA assesses not only the harmful effects of the substance on human health and environment but also their exposure potential [55]. Canada's ERA considers the lethality, mutagenicity, reproductive effects, and organ toxicity of the drug. This detailed testing weighs the impact of ANPs and is not carried out in the EU or USA. In Canada, PEC is calculated using the following Equation (3) [55].

$$
\mathrm{PEC}_{\mathrm{SW}}=(\mathrm{kg} \text { of } \mathrm{API} / \text { year }) \times(1 \text { year } / 365 \text { days }) /(\text { Wastewater } \mathrm{L} / \text { day } \cdot \text { capita }) \times(\text { population })
$$

where, PEC $\mathrm{SW}_{\mathrm{S}}$ : predicted environmental concentration in surface water $(\mu \mathrm{g} / \mathrm{L}) ; \mathrm{kg}$ of API/year: amount produced per year (kg/year); Wastewater L/day.capita: volume of wastewater generated per day per capita (L/day). The substance tested is designated to be toxic when PECsw divided by predicted no-effect concentration (PNEC) is $\geq 1$.

One major obstacle in assessing the risk of ANPs in the environment is that the existing ERA procedures differ significantly in the European Union (EU), USA, and Canada. The most notable distinction is that the EU and USA regulate products (drug), whereas Canada regulates substances (active pharmaceutical ingredients (APIs)) [55]. In EU and USA, existing drugs or new drug applications before the introduction of the ERA guidelines are not required for assessment whereas in Canada all substances entering or which may enter the environment are premised to be toxic until evaluation [55]. The EU and USA have implemented a tiered approach in which only the drugs that are suspected to be toxic are transferred onto the next stage of assessment. Canada, on the contrary, has adopted a classification-based approach in which the timing of notification is determined by the type of substances, i.e., polymer, chemical, or biological living systems [55]. However, in Canada, toxic and even non-toxic substances are checked for their accumulation impact to the land and water. The criteria of toxicity testing even after ERA clearance is vital as accumulation or circumstances of exposure to the substance may render the substance toxic. Table 2 gives a comparison of ERA procedures implemented in the USA, EU, and Canada.

Table 2. Characteristics of Environmental Risk Assessment (ERA) regulatory approach implemented in USA, EU, and Canada.

\begin{tabular}{|c|c|c|c|}
\hline & USA & EU & Canada \\
\hline $\begin{array}{l}\text { Implementing } \\
\text { organization }\end{array}$ & $\begin{array}{l}\text { Food and Drug Administration } \\
\text { (FDA) }\end{array}$ & $\begin{array}{l}\text { European Medical Agency } \\
\text { (EMA) }\end{array}$ & $\begin{array}{l}\text { Health Canada and } \\
\text { Environment and } \\
\text { Climate Change Canada }\end{array}$ \\
\hline Regulated product & $\begin{array}{l}\text { All drugs manufactured for sale in } \\
\text { EU member states }\end{array}$ & New Drugs & New Substances \\
\hline Timing of ERA & $\begin{array}{l}\text { When applying for marketing } \\
\text { approval }\end{array}$ & New Drug applications [56] & Before notification \\
\hline ERA Methodology & $\begin{array}{c}\text { Phase-tiered based approach (Phase } \\
\text { I; Phase II-Tier A and Tier B) }\end{array}$ & $\begin{array}{c}\text { Tiered based approach (Tier 1, } \\
\text { Tier 2, Tier 3) }\end{array}$ & $\begin{array}{l}\text { Classification based } \\
\text { approach (polymers, } \\
\text { living organisms, } \\
\text { chemicals) }\end{array}$ \\
\hline Drug exclusion criteria & $\mathrm{PEC}^{\mathrm{a}}<10 \mathrm{ng} / \mathrm{L}$ & $\mathrm{EIC}^{\mathrm{b}}<1000 \mathrm{ng} / \mathrm{L}$ & $\mathrm{PEC}<100 \mathrm{ng} / \mathrm{L}$ \\
\hline $\begin{array}{l}\text { Risk Assessment } \\
\text { Criteria }\end{array}$ & $\mathrm{PEC} \mathrm{PNEC}^{\mathrm{c}} \geq 1$ & $\mathrm{EC}^{\mathrm{d}}{ }_{50} / \mathrm{MEEC}^{\mathrm{e}}<10$ & $\mathrm{PEC} / \mathrm{PNEC} \geq 1$ \\
\hline Strengths & $\begin{array}{c}\text { Responsibility lies with government } \\
\text { Tiered approach }\end{array}$ & $\begin{array}{l}\text { Responsibility lies with } \\
\text { government } \\
\text { Tiered approach }\end{array}$ & $\begin{array}{l}\text { Responsibility lies with } \\
\text { government } \\
\text { Analyzes substances that } \\
\text { are presumed to be } \\
\text { non-toxic. }\end{array}$ \\
\hline Weaknesses & $\begin{array}{l}\text { No ERA for existing drugs. } \\
\text { Non-consistent ERA procedure } \\
\text { between member states }\end{array}$ & No ERA for existing drugs & Non-tiered approach \\
\hline
\end{tabular}

Notes: ${ }^{a}$-Predicted environmental concentration (for details see Section 4 of the review); ${ }^{b}$-Environment Introduction Concentration (for details see Section 4 of the review); c-Predicted no effect concentration

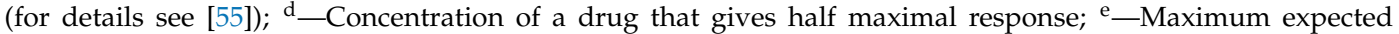
environmental concentration. 
Some ERA studies elucidated that ANP drugs that directly interact with DNA do not have any safe threshold concentrations [22,55,57], and as such the stipulated PEC and EIC values may give false positives for certain ANP drugs. For instance, Kidd et al. [58] showed that concentration of breast cancer drug $17 \alpha$-ethynylestradiol (in the concentration range 5-6 ng/L) impacted reproductive health in the fish (Pimephales promelas), that lead to a decline in its population at a concentration lower than the EMA suggested toxic level (10 ng/L).

One major issue with accurate ERA is the persistence and accumulation of some ANP drugs in the environment over time. The recalcitrant nature of some ANP drugs in activated sludge environment indicates the possibility of these compounds being persistent in river water $[19,59]$. The analysis of data provided by the German Environmental Agency confirmed that nearly 30\% of ANP compounds are persistent in the water phase [19]. This persistence may gradually increase the actual environmental concentration. Rowney et al. [57] showed that alkylating ANP drugs (0-145 ng/L), antimetabolite ANPs (0-27.4 ng/L), and anthracycline ANPs (0-0.7 ng/L) were detected in the Thames catchment in the United Kingdom. Similarly, the data available for the measured environmental concentration of cyclophosphamide in surface water varies from a negligible 0.05 to $64.8 \mathrm{ng} / \mathrm{L}$ [40].

Since there are a large number of ANP drugs currently in the market, and several others in the pipeline (Figure 1), it is necessary to categorize ANPs that are widely prescribed and are likely to persist in the environment. In addition to persistence, the current ERA methodologies do not have any guidelines on dealing with the transformation products (TPs) or human metabolites (HMs) of these drugs. It is not possible to design strategies to study the toxicity of TPs beforehand as the generation of TPs depends on the type of remediation methods employed and environmental parameters such as $\mathrm{pH}$, temperature, type of remediation technique, etc. [22]. Some studies have suggested that TPs or HMs, in some cases, may be more toxic than the parent drug [40,60]. Besse et al. [40] reasoned that the metabolites of ANP drug methotrexate could be more toxic than their parent drug. Similarly, the TPs of certain medications can be more active, even more polar, and therefore of higher mobility in aquatic environments than the parent drug [61]. Consequently, it seems plausible to redesign the current ERA methodologies keeping in mind the toxicity of HMs and TPs. Genotoxicity assessments of ANPs and their relevant TPs should be conducted to allow for a better development of biodegradation or a combination of both biotic and abiotic remediation techniques.

\section{Overview of Existing Methodologies of ANPs Degradation in Environment}

\subsection{Biological Treatments}

Microbial systems are known to synthesize certain pharmaceutical drugs and harbor efficient molecular mechanisms that make them resistant to these compounds [62]. Various studies have documented the presence of drug-resistant microbes in hospitals, agriculture, and animal husbandry where these drugs have been used to treat microbial infections [63-65]. Microorganisms evolve numerous biochemical mechanisms to counteract the toxicity of pharmaceutical drugs. Some general mechanisms that microbes exploit to resist pharmaceutical drugs are (a) variation of sites where drugs are targeted, (b) alteration of enzymes that inactivate antimicrobials, (c) reduced membrane permeability, and (d) dynamic and active efflux of pharmaceuticals [66].

Some microbial enzymes mimic the mammalian enzymes that perform xenobiotic detoxification and thus can serve as useful models of drug metabolism [67]. For instance, soil microbes, especially Actinobacteria, synthesize and secrete molecules that exhibit anticancer activity into their niche [68]. The presence of such anticancer molecules, which are a vital component of ANP drugs, accentuates other soil bacteria to harbor mechanisms to avoid the toxic effects of these drugs in their natural habitat. The use of soil bacteria to detoxify ANPs is a potent and under-investigated strategy to detoxify anticancer drugs. 


\subsubsection{Fungal and Bacterial Biodegradation of ANPs}

Currently, limited numbers of fungal and bacterial species are known to be an excellent degrader or inactivator of ANPs. Such establishment gives the proof of principle that microorganisms can modify or degrade ANPs. The white-rot fungus, Trametes versicolor, is known to have a unique capability of removing a wide variety of ANP compounds [69,70]. In one study, Ferrando Climent et al. [70] explored the possibility of eliminating some selected ANPs from sterile and non-sterile hospital wastewater in a $10 \mathrm{~L}$ fluidized bed bioreactor inoculated with the fungus T. versicolor. Maximum removal (in non-sterile wastewater) was observed for Azathioprine (AZT) $(100 \%)$, Etoposide (ETS) $(100 \%)$, and Ciprofloxacin (CIP) $(97 \%)$, whereas minimum removal was observed with TAM $(48 \%)$, but no degradation or sorption was recorded for cyclophosphamide (CP) and Ifosfamide (IF). More efficient removal of some ANPs in non-sterile wastewater possibly resulted from positive interactions between the fungi and common fecal bacteria which led to synergistic degradation of the ANP drugs. No biodegradation of IF and CP can be attributed to the halogenated atoms in their molecular structure which probably hindered aerobic biodegradation since halogenated functional groups decrease electron density at the reaction site [71]. For tamoxifen, no conclusive evidence was found for its low biodegradation in non-sterile wastewater.

On the contrary, TAM was degraded more rapidly in sterile wastewater. This increased degradation coincided with increased fungal activity in the absence of other competing microorganisms. However, the most prominent mechanism of TAM removal was attributed to sorption process since the heat-killed experiment showed $94 \%$ removal after 9 days. The high sorption of TAM in contrast to IF and CP was because of its high hydrophobicity $\left(\log \mathrm{K}_{\mathrm{ow}}=6.3\right)$. In addition, the presence of electron-donating amino group and the absence of halogenated functional groups in TAM also increased its degradation rate in sterile wastewater. In both sterile and non-sterile hospital wastewater, highest laccase activity was reached at the end of the treatment, indicating that $T$. versicolor was active throughout the experiment.

In another study, the fungus T. versicolor was used to biodegrade $10 \mathrm{mgL}^{-1}$ of sulfonamides sulfapyridine (SPY), and sulfathiazole (SPZ) [72]. Sulfonamides constitute an important class of drugs that show substantial anticancer activity [73]. SPY was completely removed after $24 \mathrm{~h}$ whereas the removal of STZ was slower and around $20 \%$ of STX was detected even after $72 \mathrm{~h}$. Unlike in the study by Ferrando Climent et al. [70], where TAM was removed by sorption to heal-killed controls, no sorption of SPY and SPZ was observed when heat-killed controls were used in this study. This suggests that the fungus T. versicolor utilizes different mechanisms of ANP detoxification/degradation depending on the nature of the drug. The presence of TPs of SPY and SPZ confirmed that the elimination of these drugs was due to biodegradation and not due to sorption. The study indicated that the enzyme laccase played an important role in biodegradation. When cell-free purified laccases with mediators were tested for biodegradation capabilities, elimination ranged from $75 \%$ to $98 \%( \pm 4 \%)$ for SPY and $82 \%$ to $100 \%( \pm 3 \%)$ for STZ by the end of the experiment.

The use of mediators such as violuric acid and ABTS enhances biodegradation as they favor the oxidation of non-phenolic compounds such as sulfonamides [74]. Though the fungus does not release these mediators, similar molecules with analogous functions may be released during active growth [72]. In addition to laccase, cytochrome P450, an intracellular enzyme complex, was also implicated in biodegradation of STZ. Culture of T. versicolor containing inhibitors of cytochrome P450 decelerated biodegradation of STZ whereas the presence of such inhibitors did not show any appreciable effect on the degradation of SPY. These results indicate that cytochrome P450 was involved in the degradation of STZ whereas there was no experimental evidence for its role in the degradation of SPY. The authors concluded that the use of whole fungal cells with active cytochrome P450 resulted in shorter degradation time. In contrast, with the use of purified laccases, significant biodegradation was seen only with longer incubation times (9-16 days) [70,75]. Laccase mediated degradation has also been shown for other ANPs such as naproxen (NPX) [76]. Naproxen is a non-steroidal inflammatory drug shown to exhibit ANP activity [77]. Biodegradation experiments with purified laccase from T. versicolor plus mediators showed almost complete degradation of NPX (95\%) at a concentration of $55 \mu \mathrm{g} / \mathrm{L}$ [76]. This study on NPX highlighted the importance of adding mediators during biodegradation in the 
presence of laccase. Purified laccase (1000 AU/L) without mediators degraded less than 10\% of NPX whereas when mediator (1-hydroxybenzotriazole) was added extensive degradation of NPX (>95\%) was detected. The study also established that inhibition of cytochrome P450 decreased the active uptake of NPX by T. versicolor and that cytochrome P450 plays a crucial role in the degradation of NPX and other ANPs.

In addition, fluorinated ANPs such as 5-FU and Citalopram (CTP) tend to be more recalcitrant in nature due to the strong C-F bond. For biodegradation of fluorinated drugs, the cleavage of $\mathrm{C}-\mathrm{F}$ bond is required. CTP, a fluorinated drug was degraded entirely after 14 days at a concentration of $1 \mathrm{mg} / \mathrm{L}$ using three white-rot fungi: Bjerkandera sp. R1, Bjerkandera adjusta, and Phanerochaete chrysosporium [78]. Biotransformation of many fluorinated compounds such as fluorophenol, fluorobenzene, and fluorobenzoic acid by aerobic microorganisms is reported [79,80]. Many oxidative enzymes are known to oxidize fluorinated derivatives of natural substances. In contrast to CTP5-FU was not readily biodegradable by T. versicolor and inoculum from the effluent of STP [78]. In fact, some fluorinated drugs require advanced photo-oxidation treatment for degradation [81]. This is because the position of fluorine on the fluorinated drug impacts its catabolism, and the position of fluorine might result in the formation of non-biodegradable dead-end metabolites [82].

Actinomycetes exhibit positive potential in degrading the ANP doxorubicin, which belongs to the anthracycline class of anticancer drugs [83]. Actinomycetes, a phylum of Gram-positive bacteria, are morphologically similar to fungi because of their elongated cells that branch into filaments or hyphae [84]. Westman et al. [83] examined Actinomycete isolates for their resistance against ANP, 67\% of these strains were resistant for up to $150 \mu \mathrm{g} / \mathrm{mL}$ doxorubicin (DOX). Interestingly, Streptomyces sp. strain WAC04685 could degrade DOX at concentrations higher than $200 \mu \mathrm{g} / \mathrm{mL}$ to a deglycosylated alcohol derivative (7-deoxydoxorubicinol) which is a non-toxic residual. The study also highlighted that the deglycosylation of doxorubicin by strain WAC04685 is mediated by the NADH dehydrogenase component of the respiratory electron transport complex I, and the addition of NADPH to crude extracts improved the degradation of DOX. The study of the purified enzyme NADH dehydrogenase revealed the involvement of three subunits (NuoE, NuoF, and NuoG), among which, only NuoF was predicted to have NADH binding function [85]. Furthermore, strain WAC04685 could catalyze reactive oxygen species that resulted from Doxorubicin by the action of two homologs superoxide dismutases, two catalases, and a glutathione peroxidase. genome. This study on DOX inactivation gives directions to further explore and engineer novel biodegradation strategies involving Actinomycetes.

In separate research on studying colon cancer models, the bacteria Mycoplasma hyorhinis could metabolize the chemotherapeutic drug gemcitabine (GEM) ( $2^{\prime}, 2^{\prime}$-difluorodeoxycytidine) into its inactive form, $2^{\prime}, 2^{\prime}$-difluorodeoxyuridine [86]. The inactivation of the GEM was dependent on the enzymatic reaction of cytidine deaminase $\left(\mathrm{CDD}_{\mathrm{L}}\right)$. Besides $M$. hyorhinis, 13 other Mycoplasma species exhibited the ability to inactivate GEM completely. The majority of these species express $\mathrm{CDD}_{\mathrm{L}}$ for such purpose indicating the importance of this enzyme in inactivation of GEM.

\subsubsection{Biodegradation of Antineoplastic Drugs in Sewage Treatment Plants (STPs)}

ANPs residues can be removed from the aqueous phase in STPs either by biotic (biodegradation or biotransformation) or abiotic (sorption, photolysis, hydrolysis) processes [87]. Specifically for ANPs, different values for their removal in wastewater treatment plants were published earlier $[40,88,89]$. The removal rate can range anywhere between $10 \%$ and $90 \%$ [89,90]. The removal efficiency at STPs ( $F_{\text {WWTP }}$ ) varies widely because $F_{\text {WWTP }}$ is dependent on various factors such as locations of the served population, capacity, configuration, type of treatment, operating parameters, and hydraulic and solid retention times [91]. It is therefore necessary to decentralize data collection procedures at STPs, and whenever possible, specific experimental data of the STP operating in the study area should be used. Furthermore, important physical-chemical parameters such as volatilization, mixing, adsorption, and degradation should be considered to estimate $F_{\text {WWTP }}$ as stipulated by the United States Environmental Protection Agency (US-EPA) and European Union System for the Evaluation of 
Substances (EUSES) [91]. In addition to the factors already mentioned, the removal rate in STPs greatly varies among different ANP drugs and the efficiency of biodegradation is associated with the drugs and its physicochemical properties (hydrophobicity, solubility etc.) [21]. Elimination rates of some ANPs detected in STPs ranges from 10-88\% (CP, ifosfamide (IF), CPC, TAM, and cytarabine (CTB)) to $77-100 \%$ (DOX, doxetaxel (DOX), ETS, GEM, ITN, CP, paclitaxel (PAC), megestrol [92], 5-FU, and MTX) clearly indicating that physicochemical properties of the drug impacts biodegradability [93]. Before jumping into the specifics of some STP studies on a few selected ANPs, it is necessary to understand that operation details on the fate and behavior of various ANPs in STPs are not provided in many studies, and as such no concrete conclusions can be drawn regarding this issue [93]. Some of the most commonly used ANP drugs and their removal during conventional biological treatment (STPs) are discussed in the following paragraphs.

Removal of Alkylating Agents in STP

Alkylating agents are a class of ANP drugs that prevent cell division primarily by cross-linking strands of DNA, and thereby inhibiting RNA and protein synthesis [94]. IF and CP are the most widely consumed alkylating agent type of ANPs, and several studies with conflicting results regarding their biodegradation have been published in literature [25,41,95-97]. In one of the early studies conducted in a laboratory scale sewage treatment plant (LSSTP), the result suggested that activated sludge did not appear to acclimatize to the presence of $\mathrm{CP}$ in the media and the drug was not efficiently biodegraded in LSSTP [25]. During the 39 days of operation (10 $\mu \mathrm{g} / \mathrm{L}$ cyclophosphamide added/day), an average of $83 \%$ of undegraded CP was recovered in the effluent [25].

On the other hand, significantly high removal of IF and CP (100\%) was recorded in some other studies [93]. IF (between 3 and $2 \mathrm{ng} / \mathrm{L}$ ) and CP (up to $13.1 \mu \mathrm{g} / \mathrm{L}$ ) have been found in the influent streams of STPs in Spain [93]. In the treated effluent streams, their concentration ranged from 0.09 to $71 \mathrm{ng} / \mathrm{L}$ for IF and 0.19 to $25 \mathrm{ng} / \mathrm{L}$ for $\mathrm{CP}$, respectively [93]. The efficiency of removal is far exceeded to that of the result obtained in a study in Slovenia that merely removed 10\% [98]. For IF, a higher removal efficiency of up to $87 \%$ in a STP in Switzerland [41], but less than 3\% in a Chinese STP [99], whereas the maximum removal of CP was $100 \%$ in a Spanish STP [93], and the lowest removal was $10 \%$ in a STP study in Slovenia [98]. The varying elimination efficiency of CP and IF can be attributed to their different physicochemical properties ( $\mathrm{K}_{\mathrm{ow}}$. water solubility, $\mathrm{pKa}$, etc.). Moreover, the microbiota of STPs and concentration of these drugs in sewage varies geographically, and therefore no conclusions can be obtained regarding the efficiencies of these treatment plants. It should also be noted that in some studies these ANPs were detected in the effluent streams but were negligible in the influent streams of the STP process $[26,100]$. This paradox could be because in influent streams these drugs are present as conjugates (not detected as free drugs in influent streams) whereas in the effluent streams these conjugates are broken down and free drugs are thus detected [101].

\section{Removal of Antimetabolites in STP}

Antimetabolites are another class of ANP agents that are structural analogs of natural substances (such as vitamins, nucleosides, or amino acids) that compete with the natural substrate for the active site on an essential enzyme or receptor, thereby interfering with the DNA synthesis [102]. 5-FU, GEM, CTB, and MTX are another widely consumed group of ANP drugs belonging to the class antimetabolites that have been investigated so far [93]. Complete elimination of 5-FU present at an initial concentration of $5 \mathrm{mg} / \mathrm{L}$ was observed in Germany [103]. These results were corroborated by other studies where 5-FU was not detected in the influent or the effluent wastewater of four Spanish WWTPs, one Swiss, and one in Baltimore [93]. The absence of 5-FU in the influent stream can probably be explained by the fact that it is swiftly metabolized and produces biologically inactive metabolites [104].

In an STP in Slovenia, 5-FU was detected inside the influent wastewater at very low quantity $(<3.1 \mathrm{ng} / \mathrm{L}$ ) with up to $100 \%$ removal efficiency after the biological treatment. The removal of $3.5 \mathrm{ng} / \mathrm{L}$ 5-FU in a Spanish WWTP was also 100\% [98]. Both findings stated above may indicate that 5-FU is 
highly biodegradable at low concentrations. However, at higher levels (20 and $100 \mathrm{mg} / \mathrm{L}$ ), 5-FU is partially biodegraded, and the TPs produced could be toxic [105]. In contrast to the results mentioned above, Kümmerer and Al-Ahmad [26] and Yu et al. [106] elucidated that 5-FU was persistent to biodegradation. Yu et al. [99] observed incomplete removals of 5-FU, even at lower concentrations ( 1 and $50 \mu \mathrm{g} / \mathrm{L})$. Amid these contrasting results, Straub [107] critically evaluated available data regarding 5-FU biodegradability tests and suggested since biodegradability of 5-FU was conducted using different treatment methods in different laboratories it is challenging to compare biodegradation rates [108]. Lutterbeck et al. [81] reasoned that the difference in biodegradability of 5-FU was due to the varying initial bacterial population density. All the tests conducted with higher bacterial densities [105] showed faster elimination of 5-FU; whereas an analysis with lower bacterial densities showed the persistence of 5-FU.

Bioremediation studies for GEM (another antimetabolite) is scarce. The removal of GEM ranged from $25 \%$ to $100 \%$ during biological treatment [98,109]. Martin et al. [110] detected a higher concentration of GEM in treated effluents $(65-88 \mathrm{ng} / \mathrm{L})$ to that of the untreated influents $(39-52 \mathrm{ng} / \mathrm{L})$. Higher concentration in the influent stream was because GEM was present in conjugate form in influent streams whereas it was dissociated into free drug in the effluent stream [93].

For CTB, the elimination rates ranged from $24 \%$ up to $64 \%$, and it was detected in quite high quantity in both influent and effluent streams $[19,110]$. For example, in samples taken from four Spanish STPs, the average influent and effluent concentrations were 464 and $190 \mathrm{ng} / \mathrm{L}$, respectively [110]. The higher level in the influent stream was possibly due to conjugated CTB, as explained in detail before. Nevertheless, it should be noted that compared to other ANP drugs, neither cytarabine nor gemcitabine may possess mutagenicity or teratogenicity according to the International agency for research on cancer [93].

Lastly, another antimetabolite ANP that is widely used is MTX. Kosjek et al. [111] described the biotransformation of MTX in an aerobic conventional activated sludge (CAS) type STP. The findings in that study suggested that MTX was readily biodegradable and transformed into several TPs. Methotrexate is consumed faster by the microbes in the presence of nutrients. The high biodegradability of MTX can also be attributed to the fact that this drug is a weak carboxylic acid, and thus it is mostly dissociated at environmental $\mathrm{pH}$. MTX is sufficiently removed by biodegradation in STPs, achieving complete degradation in some studies [96,112]. In general, the influent concentration of MTX ranged from 2.6 to $303 \mathrm{ng} / \mathrm{L}$, while its effluent concentrations from $<0.08$ to $53 \mathrm{ng} / \mathrm{L}$ [93]. Nevertheless, based on the limited data on removal of antimetabolites, no concrete conclusion can be drawn regarding their elimination in STPs, and therefore more conclusive biodegradation studies are required to confirm the biodegradability of such antimetabolites.

\section{Removal of Plant Alkaloids in STP}

Plant alkaloids are nitrogen-containing organic compounds obtained from specific plants and used as an ANP agent in the treatment of cancer [113]. These plant alkaloids attack cells at different phases of cell cycle and inhibit cell division. Docetaxel (DOC), ETS, PAC, vincristine (VIN), and ITN are five major plant alkaloids that have been studied regarding their elimination through biological processes. Almost complete removal of DOC $\left(\log \mathrm{K}_{\mathrm{ow}}=2.83\right)$ was observed in a CAS type STP in a study in Spain where its effluent concentration was lower than $3.8 \mathrm{ng} / \mathrm{L}$ as compared to its influent concentration (65-219 ng/L) [112]. For ETS, highest removal in a CAS type STP is reported to be between $77 \%$ and $100 \%$. The influent concentrations of ETS in these studies were in the range $15-83 \mathrm{ng} / \mathrm{L}$, whereas the effluent concentration was in the range $2.9-3.5 \mathrm{ng} / \mathrm{L}[95,109,110]$. ETS is primarily observed at high concentrations in hospital effluents $(\approx 714 \mathrm{ng} / \mathrm{L})$, and it was not detected in the influent or effluent streams of some domestic STPs in Spain and Slovenia $[96,98,112]$. This is probably because the use of ETS as a chemotherapeutic agent generally requires hospitalization [93]. The occurrence and removal of PAC has only been studied once by Ferrando-Climent et al. [112]. 
PAC (log $K_{\text {ow }}$ : 3.95) was detected (18 ng/L) only in one of three influent streams of a CAS type STP in Spain whereas it was not detected in effluent streams suggesting its complete removal. Complete elimination of another plant alkaloid, ITN, was observed in a CAS type STP with tertiary treatment in Spain with an influent concentration of up to $21.3 \mathrm{ng} / \mathrm{L}$ [96]. ITN was also detected in the influent stream ( $49 \mathrm{ng} / \mathrm{L})$ of a CAS type STP in Slovenia where it was almost completely degraded as the effluent concentration was less than $0.4 \mathrm{ng} / \mathrm{L}$ [98]. The biotransformation of the another plant alkaloid vincristine was also recently investigated [114]. The study showed that vincristine was readily biodegradable in CAS. This study observed that the presence of a nutrient-rich medium accelerated biodegradation rate. However, the study cautioned that the biodegradation rates could appreciably slow down if the microbial consortia present is inhibited due to the presence of some other drug which is toxic. Therefore, it is necessary to design systems keeping in mind the presence of other drugs in the system. The high removal efficiency of plant alkaloids observed in all these studies is possibly due to its high sorption to sewage sludge due to hydrophobic (low $\log \mathrm{K}_{\mathrm{ow}}$ value) and ionic interactions as suggested by Kosjek and Heath [4].

\section{Removal of Antitumor Antibiotics in STP}

Antitumor antibiotics are amongst the most important ANP agents administered for chemotherapeutic purposes. They mainly to bind to DNA or RNA through intercalation and stop cancer cells from growing [115]. DOX and epirubicin [116] are the only two antitumor antibiotics that have been investigated until now [93]. Contrasting results have been obtained regarding the removal of DOX in STPs. According to the study by Martin et al. [109] in Spain, DOX was not detected in the influent (concentration below limit of detection) whereas it was detected in the range 20.3-42.4 ng/L in the effluent stream. This was probably because DOX existed in conjugated form in the influent stream. The study by Negreira et al. [96], however, found that DOX was completely eliminated from 12 STPs in Spain as the median concentration of doxorubicin changed from $2.6 \mathrm{ng} / \mathrm{L}$ in the influent stream to below limit of detection in the effluent stream. On the other hand, Franquet-Griell et al. [117] noted that DOX remained at $40 \%$ of the initial concentration, and in one more study by Martin et al. [110] DOX was detected at higher concentrations in the effluent streams of four Spanish STPs (20.3-42.4 ng/L) probably due to conjugate formation. EPI, another antitumor antibiotic was undetected in the effluent stream of three STPs in Spain while it was detected at very low concentrations (in the range $4.5-6 \mathrm{ng} / \mathrm{L}$ ) in hospital effluent in the same studies indicating EPI might be degraded or adsorbed to sewage sludge while passing through the STP [109]. This result was corroborated by the another study where EPI was neither detected in the influent or in the effluent streams of two STPs in Canada [97]. The limited and contradictory literature data for doxorubicin DOX shows that its removal from STPs is not properly understood and further investigation is required to get a lucid picture regarding its biodegradability. On the other hand, for epirubicin, it seems that it is completely degraded in a STP, however, more research is needed from different geographic locations to confirm its complete removal in a STP.

\section{Removal of Hormonal ANPs in STP}

Hormonal ANPs are another type of chemotherapeutic treatment that interferes with hormone system, in order to slow or stop the growth of cancer cells. Hormonal ANPs are used in the treatment of various hormone-dependent cancers such as breast and prostate cancer [93]. TAM and Megestrol [92] are the two mostly studied hormonal ANPs with regard to their removal from STPs. TAM is one of the most widely used ANP for breast cancer treatment. The removal of TAM was noted to be insufficient (ranging from $18 \%$ to $50.6 \%$ ) from secondary and tertiary biological treatment in STPs. The concentration of TAM in influent stream of STP ranged from 3.5 to $215 \mathrm{ng} / \mathrm{L}$ and in the effluent stream the concentration ranged from 5.8 to $13.5 \mathrm{ng} / \mathrm{L}$ in various studies $[96,98,112,118]$. Even when tertiary treatment was applied the removal efficiency of TAM was lower (37\% and $30 \%$ in STPs in Spain and United Kingdom, respectively) indicating its resistance to biodegradation [96,118]. Another most widely used hormonal ANP is MEG which is the most common progesterone used in medicine. It was 
detected in the influent of a Spanish STP at concentration ranging from 3 to $150 \mathrm{ng} / \mathrm{L}$, and achieving a significant removal of $87 \%$ through CAS treatment [119]. In the same study, MEG was the only ANP drug detected in a second STP at an influent concentration of $220 \mathrm{ng} / \mathrm{L}$ which was completely removed (100\% elimination) through biological treatment [119]. In the study by Franquet-Griell et al. [117], MEG was not detected in the effluent stream of STP indicating its complete removal. However, the study was inconclusive as to whether elimination of MEG was due to sorption onto sewage sludge or through biodegradation. When both these hormonal drugs are compared, TAM appears to be poorly biodegradable through secondary and tertiary treatment and therefore would require further investigation regarding its occurrence and toxicity in aqueous and terrestrial environments. On the other hand, MEG appears to be completely removed, however, there are contradictions regarding the mechanism of its removal (biodegradation or sorption). Therefore, further investigations focused on the mechanism of its removal is necessary.

\subsubsection{Removal of ANP Drugs Using Membrane Bioreactors}

Membrane bioreactors (MBRs) are advanced biological treatment processes that combine the CAS with a membrane filtration process [120]. Previous investigations have shown that pharmaceutical residues are often not completely removed during the activated sludge process, which makes CAS inefficient for some pharmaceuticals [121]. MBRs is a notable system as it can be operated with highly intensified biomass, high sludge retention time, lower sludge production, high effluent quality, and enhanced biotransformation and mineralization of resistant pharmaceutical compounds [93,121]. Though the total operational cost is higher for MBR systems, it is an attractive alternative waste treatment technology as it provides a more environmentally friendly effluent [93]. However, it is necessary to note that the use of MBRs for removal of ANPs at large-scale is not available and as such only pilot scale and bench-scale studies on removal ANPs have been discussed.

Mahnik et al. [48] investigated the biodegradability of four drugs, 5-FU, DOX, EPI, and daunorubicin (DAU), present in the wastewater of an oncogenic ward by elimination using activated sludge and treatment in a $1000 \mathrm{~L}$ pilot scale membrane-bio-reactor system. 5-FU was almost completely eliminated within $24 \mathrm{~h}$, and biodegradation was hypothesized to be the most plausible mechanism as 5-FU did not adsorb to suspended solids in wastewater. On the other hand, DOX, EPI, and DAU were eliminated more than $90 \%$ from the sewage sludge mainly due to adsorption. The results indicated that all the studied anticancer drugs are eliminated by sewage treatment plants, either by biodegradation or adsorption.

In another study, the removal of cancerostatic platinum compounds (CPC) CPT, CBT, OXT, 5-FU, and anthracyclines DOX, DAU, and EPI were conducted in a pilot-scale MBR system [122]. The CPC compounds were removed at a mean value of $60 \%$ due to their adsorption to sewage sludge whereas 5-FU and the three anthracyclines were removed below limit of detection within $24 \mathrm{~h}$ mainly due to the adsorption by the MBR system. In addition, the genotoxicity of the CPC compounds was reduced in the effluent. Delgado et al. [123] studied the removal of $\mathrm{CP}$ and its principal metabolite 4-ketocyclophosphamide (4-ketoCP) in a laboratory scale MBR. The pharmaceutical removal efficiency for $\mathrm{CP}$ remained quite stable at $80 \%$, largely due to adsorption and biodegradation. On the other hand, the concentration of 4-ketoCP was higher in the reactor than in the feed, and its removal efficiency decreased from day 35 to day 66 largely due to the conversion of $\mathrm{CP}$ to its metabolite 4-ketoCP indicating further downstream treatment may be required.

In another study, CP was removed up to $80 \%$ in a pilot-scale crossflow MBR from urban effluents. However, toxicity was observed in the effluent stream, indicating that further post-treatment is required to eliminate effluent toxicity [124]. On the other hand, insignificant removal of $C P(\approx 20 \%)$ was observed in the effluents of hospital wastewater treated in a pilot-scale MBR, though, no reason was given for its low removal efficiency [125]. The cause could be due to the fouling of the membranes in MBR as observed during the removal of $\mathrm{CP}$ by Avella et al. [126]. The transmembrane pressure increased significantly (3-fold increase) due to fouling of the membrane as CP was added to the urban wastewater. 
The increased fouling was possibly due to increased exopolysaccharide or other microbial product synthesis caused by stress due to the presence of CP [127].

In a more recent study, the removal efficiency of eight ANP drugs was investigated in an anaerobic osmotic MBR (AnOMBR) [128]. AnOMBR is an innovative technology that combines biological treatment with forward osmosis (FO) under anaerobic conditions [129]. AnOMBR is highly efficient because of its low energy demand, high organic loading, and methane production [130]. Wang et al. [128] observed high removal rates (>95.6\%) for all the eight investigated ANP drugs. A high removal rate was ensured due to the high rejection of the FO membrane combined with the extended organic retention time in the reactor. DOX, EPI, and TAM were almost eliminated through adsorption, while MTX and CP were eliminated by biodegradation and FO rejection, respectively. MTN, AZT, and Flutamide (FLT) were eliminated by both biodegradation and adsorption to anaerobic sludge. However, there are disadvantages associated with AnOMBR as envisaged in the study by Wu et al. [131]. In that study, it was observed that the presence of ANPs caused the inhibition of microbial metabolism. At the same time, marginally changing microbial community's composition, while the extracellular polymeric substances (EPS) concentration was increased. The increased EPS production caused severe biofouling and significantly increased transmembrane pressure.

The level of STP processing (primary, secondary, and tertiary treatment) is not mentioned in many of the studies. Therefore, the removal efficiencies cannot be compared for the different studies reviewed above. The concentrations and the removal rates of these ANPs (specifically the two alkylating agents) vary significantly through the WWTPs worldwide, making it difficult to conclude if these compounds are highly resistant or not to biological treatment. However, most of the available studies so far indicated that the removal rates of these two alkylating agents through conventional processes are lower than $65 \%$, showing that there is a need for subsequent post-treatments.

Furthermore, when compared to STP-CAS systems, higher removal efficiency seems to be observed in MBR systems in a lab- and pilot-scale. However, more studies on a larger scale are required to provide more concrete and reliable finding regarding its efficiency and total operating costs for each setup. In addition, more investigation is needed with regard to MBR effluents toxicity; though the toxicity is expected to be low because of the filtration systems, however, more data is required to confirm this hypothesis [93]. Moreover, it is also necessary to conduct microbial community analysis in the presence of various ANP drugs to understand the influence of such drugs on the composition and function of the microbial community. The removal of some regularly prescribed ANP drugs through conventional biological processes is shown in Table 3.

Table 3. Biological degradation of some widely used ANP drugs.

\begin{tabular}{|c|c|c|c|c|c|}
\hline ANP Drug & $\begin{array}{l}\text { Type of Biological } \\
\text { Treatment }\end{array}$ & $\begin{array}{l}\text { Mechanism of } \\
\text { Bioremediation }\end{array}$ & $\begin{array}{c}\text { Initial } \\
\text { Concentration } \\
(\mathrm{ng} / \mathrm{L})\end{array}$ & $\begin{array}{c}\text { \% Elimination } \\
\text { of the Parent } \\
\text { Drug }\end{array}$ & Reference \\
\hline TAM & $\begin{array}{c}\text { Fluidized bed } \\
\text { bioreactor (with } \\
\text { Trametes versicolor) }\end{array}$ & $\begin{array}{l}\text { Intracellular } \\
\text { transformation } \\
\text { by cytochrome } \\
\text { P-450 system }\end{array}$ & 970 & $91 \%$ & [70] \\
\hline IF & CAS-STP ${ }^{\text {a }}$ & N.D. & 16.4 & $45 \%$ & [99] \\
\hline FLT & $\begin{array}{l}\text { Biotransformation by } \\
\text { Caenorhabditis elegans }\end{array}$ & $\begin{array}{l}\text { Cytochrome } \\
\text { P450 mediated } \\
\text { oxidation }\end{array}$ & $9 \times 10^{7 b}$ & $50 \%$ & [67] \\
\hline $\mathrm{CP}$ & LSSTP $^{\text {c }}$ & Biodegradation & $6-143$ & $>80 \%$ & [25] \\
\hline СРC & STP & Biodegradation & 158 & $100 \%$ & [98] \\
\hline СТВ & CAS-STP & N.D. & N.D. & $24 \%$ & [19] \\
\hline DOC & CAS-STP & $\begin{array}{l}\text { Biodegradation } \\
\text { and sorption }\end{array}$ & 65-219 & $\approx 100 \%$ & [112] \\
\hline
\end{tabular}


Table 3. Cont.

\begin{tabular}{|c|c|c|c|c|c|}
\hline ANP Drug & $\begin{array}{c}\text { Type of Biological } \\
\text { Treatment }\end{array}$ & $\begin{array}{l}\text { Mechanism of } \\
\text { Bioremediation }\end{array}$ & $\begin{array}{c}\text { Initial } \\
\begin{array}{c}\text { Concentration } \\
(\mathrm{ng} / \mathrm{L})\end{array}\end{array}$ & $\begin{array}{c}\% \text { Elimination } \\
\text { of the Parent } \\
\text { Drug }\end{array}$ & Reference \\
\hline ETS & CAS-STP & N.D. & $15 \mathrm{ng} / \mathrm{L}$ & $77 \%$ & [109] \\
\hline VNB & CAS-STP & Non-biodegradable & $<\operatorname{LOD}^{\mathrm{d}}$ & $0 \% \mathrm{e}^{\mathrm{e}}$ & [110] \\
\hline PAC & CAS-STP & $\begin{array}{l}\text { Biodegradation } \\
\text { and sorption }\end{array}$ & $<$ LOD-18 & $100 \%$ & [112] \\
\hline GEM & CAS-STP & $\begin{array}{l}\text { Adsorption to } \\
\text { sewage sludge }\end{array}$ & 840 & $40-79 \%$ & [132] \\
\hline BLC & CAS-STP & N.D. & 11-19 & - & [133] \\
\hline MTN & $\mathrm{AnOMBR}^{\mathrm{f}}$ & $\begin{array}{l}\text { Adsorption and } \\
\text { biodegradation }\end{array}$ & 100 & $100 \%$ & [128] \\
\hline 5-FU & eMBR $g$ & $\begin{array}{l}\text { Biotransformation } \\
\text { and sorption }\end{array}$ & $0-1.2 \times 10^{6 \mathrm{~h}}$ & $>90 \%$ & [134] \\
\hline DOX & CAS-STP & Biodegradation & $2.5-2.7$ & $100 \%$ & [96] \\
\hline
\end{tabular}

Notes: Tamoxifen: TAM; Ifosfamide: IF; Flutamide: FLT; Cyclophosphamide: CP; Capecitabine: CPC; Cytarabine: CTB; Docetaxel: DOC; Etoposide: ETS; Vinorelbine: VNB; Paclitaxel: PAC; Gemcitabine: GEM; Bleomycin: BLC; Mitotane: MTN; 5-Fluorouracil: 5-FU; Doxorubicin: DOX. ${ }^{a}$ Conventional activated sludge type sewage treatment plant; N.D. not determined in the study; ${ }^{\mathrm{b}}$ The experiment was conducted in a conical flask (5 mg flutamide dissolved in $50 \mathrm{~mL}$ broth and $5 \mathrm{~mL}$ culture); ${ }^{\mathrm{c}}$ Laboratory scale sewage treatment plant; ${ }^{\mathrm{d}}$ Limit of detection; ${ }^{\mathrm{e}}$ vinorelbine showed high concentration in effluent wastewater (up to $170 \mathrm{ng} / \mathrm{L}$ ); ${ }^{\mathrm{f}}$ Anaerobic osmotic membrane bioreactor; $\mathrm{g}$ External membrane bioreactor; ${ }^{\mathrm{h}}$ The concentration in the study was in range $0-1287 \mu \mathrm{g} / \mathrm{L}$.

\section{Removal of ANPs Using Abiotic Methods}

As discussed earlier, the elimination of ANP agents by conventional wastewater treatment such as CAS and MBR is often incomplete and inefficient. The reason is that some of these ANP drugs are resistant to biodegradation, have low adsorption efficiency, and tend to generate TPs [21,135]. In addition, some researchers believe that despite excellent removal efficiency $(>80 \%)$ of biological methods, ANP agents might have adverse effects on all eukaryotic organisms even at deficient concentrations due to their toxicological properties $[1,22,40]$. Further, due to the possibility of occurrence of ANP drugs in potable water, their complete elimination is of high importance. In this sense, abiotic treatment methods such as chemical, filtration, and other oxidation and advanced oxidation treatments become essential as they can degrade numerous ANPs that are missed in conventional wastewater treatment. Some of these abiotic methods are explained in brief in the following sections.

\subsection{Adsorption on Abiotic Surfaces}

Various physical and chemical methods have been used for the remediation of ANP drugs. Techniques such as adsorption, membrane filtration, and electrodialysis rely on the differences in physico-chemical properties of ANP drugs [136,137]. Both polar and non-polar ANP agents in aqueous systems such as wastewater effluents can be omitted by using activated carbon in powdered or granulated forms. Chen et al. [138] analyzed the adsorption of three ANP drugs (Irinotecan (IRN), TAM, and CP) on powdered activated carbon (PAC) [139]. They inferred an inverse relationship between the hydrophobicity of the tested drugs and their adsorption on PAC with more hydrophobic drugs (lower $\left.\log \mathrm{K}_{\mathrm{ow}}\right)$ showing better adsorption (Tamoxifen $\left(\log \mathrm{K}_{\mathrm{ow}}=6.30\right)>$ Irinotecan $\left(\log \mathrm{K}_{\mathrm{ow}}=3.73\right)>$ Cyclophosphamide $\left(\log \mathrm{K}_{\mathrm{ow}}=0.63\right)$ ). More hydrophobic compounds exhibited better adsorption.

However, adsorption cannot be chosen as a standalone approach in removing all ANPs because of two reasons. (i) $\mathrm{pH}$ influences the hydrophobicity of ANPs due to which some ANPs may become ionized, thereby minimizing their adsorption efficiency [19]. (ii) The calculation of hydrophobicity is inaccurate or not possible in some cases. For instance, it is hard to know the hydrophobicity of 
protein-based ANPs; such as antibodies (ATC code L01XC) and recombinant proteins (ATC code L01XE). The distribution equilibrium of macromolecules is also $\mathrm{pH}$-dependent [19]. In general, polar compounds with $\log \mathrm{K}_{\mathrm{ow}}$ values $<1$ should not adsorb to organic matters [4]. However, interactions between polar compounds and organic matter by hydrophobic and ionic interactions cannot be neglected. It is therefore recommended that any decontamination technique being developed should consider the $\mathrm{pH}$ dependency of the drugs, including its ionizability, and physico-chemical parameters that were stated earlier in Section 2.

\subsection{Membrane Based Filtration Technologies}

Membrane-based filtration and dialysis techniques such as reverse osmosis (RO), nanofiltration (NF), ultrafiltration (UF), and electrodialysis have also been used for the removal of pharmaceutical drugs from wastewater and have given ambiguous results [21,140-144]. NF was able to efficiently remove $(>90 \%)$ negatively charged pharmaceuticals while the removal efficiency of non-charged pharmaceuticals varied widely (12\% to 99\%) [143]. Electrostatic exclusion was the main reason for the removal of charged medicines, while size exclusion was the critical mechanism for the removal of non-charged compounds [143]. Another study on the removal of CP by NF and RO membranes demonstrated that CP was efficiently $(>90 \%)$ removed when $\mathrm{RO}$ membrane was applied; however, only $20-40 \%$ removal of CP was observed when NF was operated [145]. The high elimination efficiency of the RO membrane was seen under all operating conditions with no effect of changing trans-membrane pressure, feed concentration, and water matrix on the removal rate. Though membrane-based filtration technologies have shown some success in removal of ANP drugs, they suffer from two significant drawbacks of membrane fouling and high maintenance cost due to the pressure-driven nature of these technologies [21].

Another membrane-based technology tested for degradation of ANP agents is electrodialysis $[144,146]$. Electrodialysis is a membrane-based process operated under the influence of an electric field in which ions move across a semi-permeable membrane (cation exchange or anion exchange). Electrodialysis can be used for source-based separation of residual drugs in urine in which the concentrated stream contains salts, whereas the diluted stream is rich in pharmaceutical compounds [21]. Pronk et al. [144] conducted electrodialysis experiments and observed that the adsorption of drugs depends on the ionic characteristics (acidic or basic), in addition to the hydrophobicity of the compounds. The results indicated that compounds with greater hydrophobicity are easier to separate through electrodialysis.

Studies on membrane filtration-based removal of ANPs are still insufficient, and no absolute conclusions can be drawn based on the separation of a few pharmaceuticals evaluated under ideal laboratory conditions. This warrants the need for further research in designing new membranes at lower-costs and optimizing the system's operating condition.

\subsection{Chemical Treatments}

Remediation using chemical treatments has been extensively applied in the past to treat ANP wastes from hospitals but is losing popularity nowadays. Strong oxidizing (potassium permanganate and sodium hypochlorite), and alkylating agents (hydrogen peroxide and Fenton reagent) are commonly utilized chemicals [147-149]. The degradation ability of these chemicals depends mostly on the chemical structure of the drugs, and the concentration of chemicals used. Additionally, the TPs formed by chemical degradation can be mutagenic and toxic from some chemical treatments and benign from others $[147,149,150]$. Hydrogen peroxide $(30 \%, v / v)$ and Fenton reagent $(30 \%, v / v)$ have been used to degrade various ANP agents (e.g., idarubicin (IDA), DOX, EPI, pirarubicin (PIR), aclarubicin (ACL), DAU, CP, IF, and melphalan (MEL)) [148,149]. DOX and DAU were degraded entirely after an hour when using either sodium hypochlorite or Fenton reagent (a mixture of $\mathrm{H}_{2} \mathrm{O}_{2}$ and a ferrous salt), and the TPs formed were found to be non-mutagenic. In the same study, treatment with $30 \% \mathrm{H}_{2} \mathrm{O}_{2}$ led to only partial degradation (68\%) of DOX whereas complete degradation of daunorubicin was observed 
after $48 \mathrm{~h}$ of treatment [148]. However, similar studies conducted using Fenton reagent resulted in the generation of mutagenic TPs during the degradation of MEL and DAU [149,151]. Therefore, the mutagenicity of TPs generated by various chemical treatments should be tested irrespective of treatment procedure used since the mutagenicity is mostly dependent on drug type. In addition to the drug type, the drug preparation protocols have also affected the efficiency of chemical treatments in many studies [149,150]. Hansel et al. [63] found that chemical degradation of CP by Fenton oxidation in the presence of 5\% Dextrose (D5\%) generated mutagenic TPs, whereas in the absence of D5\% no mutagenic TPs were created.

Another limitation of chemical treatments is the need to quench and neutralize the $\mathrm{pH}$ after reaction for subsequent mutagenicity tests. Furthermore, due to the risk of secondary contamination with toxic chemicals used in ANP treatment, and the associated costs, scaling of these treatment methods is not feasible. Due to this concern, future research efforts should be directed towards minimizing the use of chemical treatment methods and developing an integrated technology that degrades ANP agents and prevents them from causing irreparable damage to the aquatic and terrestrial ecosystem.

\subsection{Decontamination Using Oxidation and Advanced Oxidation Methods}

\subsubsection{Oxidation Methods}

Methods such as photolysis, photooxidation, ozonation, UV treatment are the most trending oxidation methods used for degradation of ANPs $[2,81,105,152]$. Photolysis, i.e., sunlight-mediated photodegradation may occurs via direct and indirect pathways: direct photolysis occurs through light absorption by the chemical itself and leads to chemical bond cleavage. Indirect photolysis involves light absorption by dissolved organic matter (DOM) such as nitrates, nitrites, and carbonates in the aqueous environment, producing reactive species that react with target analytes (ANPs) [153].

Generally, natural attenuation under direct solar radiation cannot occur when a substance cannot absorb radiation over $290 \mathrm{~nm}$ [154]. For example, results from direct photolysis experiments conducted by Lin et al. [153], demonstrated that CP showed minimal to no absorbance in the 250-350 nm range and did not show any signs of degradation even after $24 \mathrm{~h}$ of exposure to sunlight. 5-FU, on the other hand, had a maximum absorbance at $\approx 265 \mathrm{~nm}$ and underwent direct photolysis with a half-life of $56 \mathrm{~h}$ [153]. During indirect photolysis, in the presence of nitrate $(>5 \mathrm{mg} / \mathrm{L})$ and significant amounts of bicarbonate (close to $2 \mathrm{mM}$ ), $93 \%$ of 5-FU was rapidly removed (within one day) from the sample tested, whereas CP showed minimal degradation. The degree of mineralization was another criterion used in this study to test the efficacy of photolysis. The analysis of the degree of mineralization was done through the determination of total organic carbon (TOC) which would increase if the drug reacts and incorporates with the organic matrix. Further insight into the byproducts from both direct and indirect photolysis of 5-FU revealed that photolytic degradation had transformed 5-FU into other organic substances of unknown toxicity, with no mineralization even after $42 \mathrm{~h}$ of reaction time [153]. The high 5-FU degradation and lack of mineralization further implied that photoproducts of 5-FU are likely to be less photolabile. Similar results were observed in other studies, where ANPs and other pharmaceuticals have been found to undergo only photo-transformation (no mineralization), and the TPs generated were less photolabile and more toxic $[21,135,154]$. These results challenge the validity of the current understanding of sunlight photolysis and prompts us to investigate for other efficient alternatives. Gomez et al. [155] have also shown the complexity of the photodegradation process of 5-FU, where a large number of photo-TPs were identified. This study also did not identify the toxicity of photo-TPs formed. Franquet-Griell et al. [117] studied the UV-C light photolysis of 16 widely used ANP drugs. They found that ANP drugs MEL, ETS, and prednisone (PDN) were completely eliminated by UV-C light photolysis when all of these drugs were previously passed through hydrolysis and a STP plant. The degradation was fast, and after $30 \mathrm{~min}$ of treatment none of these compounds were detected. The fast degradation was possibly due to the presence of aromatic groups in these drugs that absorbs UV light. Non-aromatic drugs such as MEG and CTB were still present at $18 \%$ and $40 \%$ of the 
initial concentration. IF and $\mathrm{CP}$ were the most refractory drugs that showed minimal degradation even after $90 \mathrm{~min}$. This suggests that if UV-C photolysis is the last step in treatment some drugs may not be removed and could be discharged to surface waters.

Some other studies that used electro-Fenton oxidation [156] and photo-Fenton oxidation [157] were able to almost completely remove refractory drug 5-FU. Electro-Fenton oxidation resulted in complete degradation of 5-FU in $7 \mathrm{~min}$. It was also noted that oxidation increased on increasing $\mathrm{Fe}^{2+}$ concentration to $0.2 \mathrm{mM}$. This was possibly because of larger production of $\mathrm{OH}^{\bullet}$ radicals at $0.2 \mathrm{mM}$. Photo-Fenton oxidation achieved $98 \%$ degradation of 5-FU in $30 \mathrm{~min}$. All the oxidation methods discussed in this section show that a more advanced and integrated treatment procedure needs to be designed depending on the whether the drugs are refractory, or whether they have aromatic side chains or not.

\subsubsection{Advanced Oxidation Methods}

Advanced oxidation processes (AOPs) can be a suitable alternative, which could result in the satisfactory elimination of ANPs. Some studies have investigated the degradation of ANP agents such as 5-FU [81,105,158]; MTX [108], bortezomib (BRZ) [152] using primarily three different advanced photooxidation processes (AOPs) individually as well in combination: $\mathrm{UV} / \mathrm{H}_{2} \mathrm{O}_{2}, \mathrm{UV} / \mathrm{Fe}^{2+} / \mathrm{H}_{2} \mathrm{O}_{2}$, and $\mathrm{UV} / \mathrm{TiO}_{2}$. Results indicated faster elimination of most of the 5-FU and MTX in all the irradiation reactions. Treatment of 5-FU with $\mathrm{UV} / \mathrm{Fe}^{2+} / \mathrm{H}_{2} \mathrm{O}_{2}$ and $\mathrm{UV} / \mathrm{TiO}_{2}$ achieved the highest degree of mineralization, whereas the lowest degree of mineralization was seen after treatment with $\mathrm{UV} / \mathrm{H}_{2} \mathrm{O}_{2}$. The low mineralization (with $\mathrm{UV} / \mathrm{H}_{2} \mathrm{O}_{2}$ ) was due to the formation of per hydroxyl radicals [81]. The TPs formed during the reactions did not show positive indications for mutagenic effects but were still toxic. However, in another AOP study conducted by Burleson and Chambers [159], the TPs formed by ozonation of $\mathrm{CP}$ were more mutagenic than the parent compound. The implications of this and other works, suggests that photolysis and AOPs, like other abiotic treatments, cannot achieve complete ANP drug remediation. A potentially efficient alternative for ANP remediation is the use of chemical and oxidation methodologies in association with biological treatments [160,161]. Biological treatments use natural biological systems for drug degradation and are therefore more environmentally safe. Though the integration of biological and AOP treatments appear encouraging, increasing the biodegradability through either partial oxidation or as a post-treatment for the degradation of persistent compounds [81], gives contradictory results. Biodegradability studies conducted by Lutterbeck et al. [81], showed negligible biodegradation of 5-FU, and thus classified the compound as not readily biodegradable. However, the compounds present in the photolytic mixture (mostly TPs) obtained after $\mathrm{UV} / \mathrm{H}_{2} \mathrm{O}_{2}$ treatment had a better biodegradability.

As observed in all these abiotic methods, all parent compounds were eliminated (either entirely or partially) but the mixture of TPs formed was toxic and non-biodegradable in many cases (Table 4). Highlights from some more studies on degradation/elimination of ANP drugs using various abiotic methods are listed in Table 4. A schematic view of the existing biotic and abiotic methods of ANP degradation is provided in Figure S1 of the Supplementary Information. The use of harsh chemicals and advanced oxidation is costly and is not environmentally benign, and it may contribute to the formation of other complex products that may be difficult to eliminate. It is therefore necessary to design efficient and sustainable treatment technologies which includes both biotic and abiotic methods, and which is environmentally friendly and is inexpensive. The next section of this review discusses one such idea that incorporates energy generation to reduce total capital cost of remediation. 
Table 4. Studies on removal of ANP agents using physico-chemical and oxidation methods.

\begin{tabular}{|c|c|c|c|c|c|c|}
\hline Treatment Process & Target ANP Drug & $\%$ Elimination & $\begin{array}{l}\text { No. of TPs } \\
\text { Formed }\end{array}$ & $\begin{array}{c}\text { Biodegradability } \\
\text { Treated Drug and Its TPs }\end{array}$ & $\begin{array}{l}\text { Change in Toxicity } \\
\text { (Drug vs. TPs) }\end{array}$ & Reference \\
\hline $\begin{array}{l}\text { Advanced (Photo)Oxidation } \\
\left(\mathrm{UV} / \mathrm{TiO}_{2}\right)\end{array}$ & DOX & $100 \%$ in $30 \mathrm{~min}$ & 17 TPs & N.D. & $\begin{array}{c}\text { Decrease in toxicity in } \\
2 \mathrm{~h}(3 \% \text { toxicity } \\
\text { reduction) }\end{array}$ & [162] \\
\hline $\begin{array}{c}\text { Advanced (Photo)Oxidation } \\
\left(\mathrm{UV} / \mathrm{H}_{2} \mathrm{O}_{2}\right)\end{array}$ & MTX & $>99 \%$ in $16 \mathrm{~min}$ & 6 TPs & $\begin{array}{c}\text { Very low } \\
\text { biodegradability }\end{array}$ & $\begin{array}{l}40 \% \text { decrease in } \\
\text { toxicity }\end{array}$ & [108] \\
\hline UV Photolysis & 5-FU & $\begin{array}{l}100 \% \text { elimination in } 32 \\
\text { min }\end{array}$ & $3 \mathrm{TPs}$ & $\begin{array}{c}\text { Increased } \\
\text { biodegradability }\end{array}$ & $\begin{array}{l}45 \% \text { decrease in } \\
\text { toxicity }\end{array}$ & [2] \\
\hline Ozonation $\left(\mathrm{O}_{3}\right)$ & $\mathrm{CP}$ & $\begin{array}{l}69.8 \% \text { at } \mathrm{pH} 9 \\
61.2 \% \text { at } \mathrm{pH} 5\end{array}$ & N.D. & N.D. & $\begin{array}{l}\text { Increase in acute } \\
\text { toxicity }\end{array}$ & [163] \\
\hline Chlorination & ERL & $95 \%$ in $1 \mathrm{~h}$ & 16 TPs & N.D. & $\begin{array}{c}\text { Increase in toxicity of } \\
\text { TPs }\end{array}$ & [164] \\
\hline Electron beam irradiation & $\mathrm{CPC}$ & $\begin{array}{c}73 \% \text { for } 50 \mathrm{mg} / \mathrm{L} \mathrm{CPC} \mathrm{and} \\
36 \% \text { for } 150 \mathrm{mg} / \mathrm{L} \mathrm{CPC}\end{array}$ & 5 TPs & N.D. & $\begin{array}{l}\text { TPs had lower } \\
\text { toxicity than parent } \\
\text { compound }\end{array}$ & [165] \\
\hline Electro-oxidation & MTX & $\begin{array}{c}100 \% \text { in } 30 \mathrm{~min} \text { at } \mathrm{CD}^{\mathrm{b}} \text { of } \\
30 \mathrm{~mA} / \mathrm{cm}^{2}\end{array}$ & 4 TPs & N.D. & Increase in toxicity & [166] \\
\hline $\begin{array}{l}\text { Photo Fenton oxidation } \\
\left(\mathrm{UV} / \mathrm{Vis} / \mathrm{H}_{2} \mathrm{O}_{2} / \mathrm{Fe}^{2+}\right)\end{array}$ & 5-FU & $100 \%$ in $1 \mathrm{~h}$ & N.D. & N.D. & Decrease in toxicity & [167] \\
\hline $\mathrm{TiO}_{2} / \mathrm{H}_{2} \mathrm{O}_{2} / \mathrm{SSL}^{\mathrm{c}}$ & СТВ & $100 \%$ in $<45 \mathrm{~min}$ & 4 TPs & N.D. & $\begin{array}{l}11 \% \text { decrease in } \\
\text { toxicity }\end{array}$ & [168] \\
\hline $\begin{array}{c}\text { Advanced (Photo)Oxidation } \\
\left(\mathrm{UV}-\mathrm{C} / \mathrm{TiO}_{2}\right)\end{array}$ & ETS & $100 \%$ elimination & N.D. & N.D. & Not tested for toxicity & [169] \\
\hline
\end{tabular}

Notes: 5-FU: 5-Fluorouracil; CP: Cyclophosphamide; IF: Ifosfamide; CIP: Ciprofloxacin; DOX: Doxorubicin; Erlotinib: ERL; Capecitabine: CPC; Cytarabine: CTB; Etoposide: ETS;

TPs: Transformation products; N.D. Data not determined in the study; ${ }^{\mathrm{b}}$ Current density; ${ }^{\mathrm{c}}$ Photochemical degradation by $\mathrm{TiO}_{2}$ photocatalysis under simulated solar light. 


\section{Possible Strategies for Improved Remediation of ANP Waste Incorporating Thermophiles}

Despite the strategies already undertaken to degrade ANP waste and considering the growing concern on efficacious ANP waste disposal, there is an urgent need of developing a systematic, efficient, and integrated degradation process for complete remediation of ANP waste (including its TPs and human metabolites). The waste treatment technologies should be chosen to take into account the origin and nature of waste, the degree of hazard attrition required, nature of TPs formed, and economics [170]. Many unexplored ideas could be used to degrade ANP waste and their TPs systematically. Some of the strategies that could be of valuable importance and have not yet been used successfully are discussed in brief in this section.

Treatment of high strength aqueous waste containing ANPs by integrating biotic and abiotic treatment methods or a combination of these have been proposed in recent years $[170,171]$. For example, when abiotic treatment methods such as UV/Ozonation was combined with biological treatment, degradation efficiency of greater than $99 \%$ was achieved for CP and IF [27]. Other methods such as source-based separation and treatment of urine [21], combined with an integrated abiotic and biotic treatment downstream can be used to minimize the concentration of ANP waste in aquatic systems. Source-based treatment of urine is separate collection and treatment of urine before discharging it into the wastewater treatment plants [172]. Source-based separation of urine also contributes toward reducing excessive nutrient release into downstream treatment plants thereby abating eutrophication, increasing the treatment efficiency of settled wastewater by $60 \%$, and ultimately increasing the life of downstream treatment plants $[21,173,174]$.

For enhanced biological transformation and mineralization of pharmaceuticals after urine separation, membrane bioreactors (MBR) [27] can be employed that have the inherent ability to process higher organic loading rates. If downstream waste treatment processes incorporating MBRs operate at mesophilic temperatures, it will create a breeding ground for pathogens and other antibiotic-resistant bacteria. To counter this concern, thermophilic decontamination techniques could be employed. Thermophilic conditions have distinct advantages over mesophilic ones, such as high organic loading and rapid removal rate of biodegradable substrates, ability to treat high strength aqueous wastes from industrial facilities containing hazardous compounds constituting ANP agents, and potential for minimal effluent discharge $[170,175,176]$. The role of thermophiles in ANP drug elimination has not been explored much but owing to the benefits of thermophiles, an efficient integrated abiotic and biotic treatment technology could employ thermophilic MBR systems for treatment of source separated urine from hospital settings.

Apart from thermophilic MBRs, another approach to enhance the biodegradation could be the use of electrochemical techniques. The electrochemical strategies provide clues for harnessing the thermophilic electroactive microorganisms for mediating the detoxification of these ANP drugs. These systems operate by applying external electrical energy for mediating the chemical transformation of these drugs. Application of specific oxidation or reduction potential will aid in microbial oxidation/reduction of these drugs at accelerated rates. Barisci et al. [177] reported an electrooxidation strategy for the degradation of ANP drug carboplatin using differently mixed metal oxide and boron-doped diamond electrodes. Experiments at different $\mathrm{pH}$ values showed that $\mathrm{Ti} / \mathrm{RuO}_{2}$ anodes degraded ANP drug carboplatin up to $49 \%$ and $75 \%$ at $\mathrm{pH} 9$ and 4 , respectively. Another study Zhang et al. [178] examined the electrochemical treatment of anticancer drugs wastewater containing 5-Fluoro-2-Methoxypyrimidine (5FMP) using a tubular porous electrode electrocatalytic reactor. They found that increasing the flow rate improved the removal efficiency of the 5FMP. Approximately 96.1\% removal of 5FMP was observed after $180 \mathrm{~min}$ at a flow rate of $0.31 \mathrm{~L} / \mathrm{min}$. This could be attributed to the fact that high flow rate enhanced the mass transfer efficiency of the drug. Such examples of electrochemical methods give a strong background for developing bio-electrochemical process employing thermophilic microorganisms for faster degradation of ANP drugs. Figure 4 shows a possible integrated ANP waste decontamination methodology using the techniques mentioned in this section. 


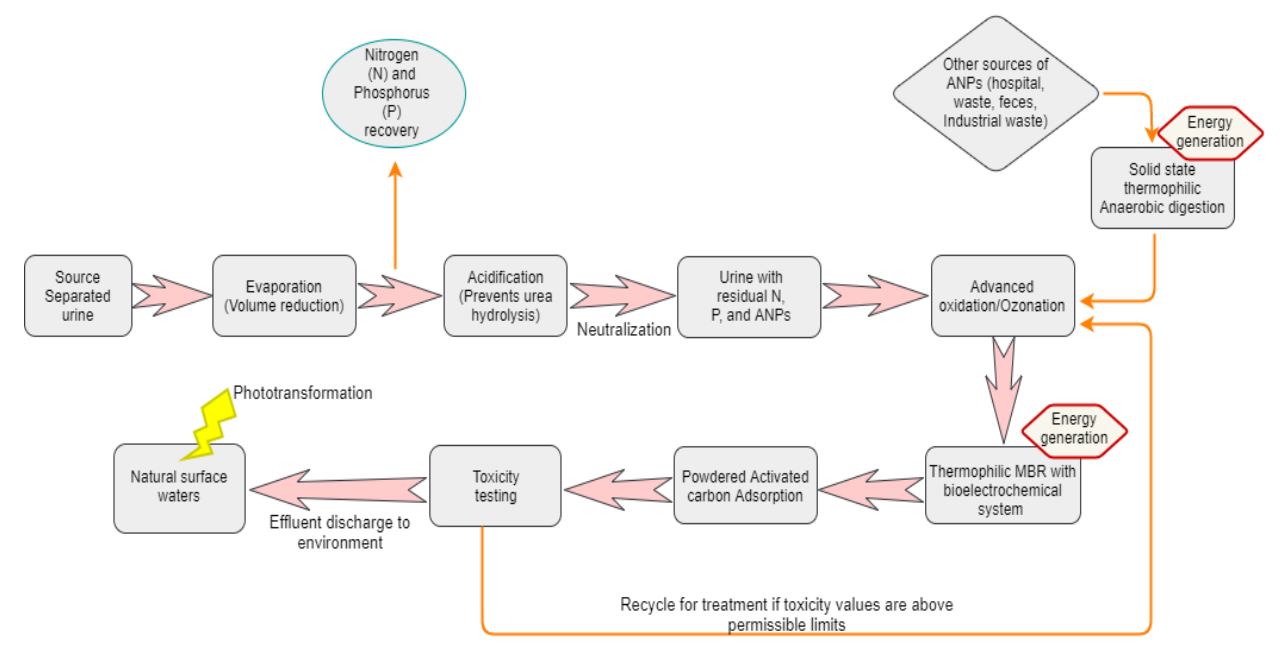

Figure 4. Proposed integrated ANP waste treatment methodology employing thermophiles.

\section{Conclusions}

This review summarizes the sources and occurrence of ANP drugs in the environment as well as the methods currently being used for their remediation to address the present challenges and future opportunities of these methods. Though these studies have explored the potential of biodegradation of ANPs, however, specific issues related to the generation of TPs and epoxides have come to light recently. For example, fungi in sewage treatment plants (STPs) generate epoxides by oxidizing aromatic hydrocarbons that can have toxic effects on human and animal health [92,179]. The toxicity and mutagenicity of the intermediate and degradation products are not reported in many of ANP biodegradation studies. TPs can be sometimes more toxic than the parent compound, and therefore toxicity studies should be conducted on TPs generated after biodegradation of the parent compound. The need for environmentally safe remediation of ANP drugs has become a paramount concern due to their increased production in the last decade. The highly toxic nature of ANP waste adversely affects the terrestrial and aquatic life. The use of expensive and harsh abiotic techniques is not environmentally friendly and often transforms the parent drug into recalcitrant TPs. Considering this, there is a need to develop an efficient and environmentally friendly remediation method. Integration of biological remediation with the non-biological techniques could be more sustainable and promising alternative for the safe removal of ANP drugs. The use of thermophilic MBRs for treatment of source-separated urine can also aid in safe-remediation of ANP drugs. Future strategies would require thorough techno-economic evaluation before implementation at large scale waste removal plants. Improved ANP degradation strategies will protect ground and surface water which in turn is crucial for the human health and agricultural sector. This will maintain the quality of irrigation products and restrict the entry of ANP waste in food cycle of higher eukaryotes, thus eliminating the chances of ANP biomagnification.

Supplementary Materials: The following are available online at http://www.mdpi.com/2227-9717/8/7/747/s1, Table S1: Raw data for global heat map on number of ANP drugs produced in 2004 and 2014 in select countries, Table S2: Raw data on age standardized number of cancer cases per 100,000 people in select countries, Figure S1: Schematic of existing methods of ANP degradation.

Author Contributions: Conceptualization: A.K.T. and R.K.S.; methodology, A.K.T., A.D., T.G. and S.R.; validation, N.K.R. and A.K.T.; formal analysis, A.D., T.G. and S.R.; investigation, A.K.T. and R.S.; resources, A.D., T.G. and S.R.; data curation, A.K.T. and R.S.; writing-A.K.T.; writing-review and editing A.K.T., A.D., T.G., S.R., K.M.G., N.K.R. and R.K.S.; visualization, A.K.T. and A.D.; supervision, R.K.S. and K.M.G. All authors have read and agreed to the published version of the manuscript.

Funding: This research was supported by the National Science Foundation (Award \# 1736255, \#1849206, and \#1920954). 
Acknowledgments: The authors gratefully acknowledge the support from National Science Foundation in the form of BuG ReMeDEE initiative (Award \# 1736255) and the Department of Chemical and Biological Engineering at the South Dakota School of Mines and Technology.

Conflicts of Interest: The authors declare no conflict of interest.

\section{References}

1. Johnson, A.C.; Jürgens, M.D.; Williams, R.J.; Kümmerer, K.; Kortenkamp, A.; Sumpter, J.P. Do cytotoxic chemotherapy drugs discharged into rivers pose a risk to the environment and human health? An overview and UK case study. J. Hydrol. 2008, 348, 167-175. [CrossRef]

2. Lutterbeck, C.A.; Wilde, M.L.; Baginska, E.; Leder, C.; Machado, Ê.L.; Kümmerer, K. Degradation of cyclophosphamide and 5-fluorouracil by UV and simulated sunlight treatments: Assessment of the enhancement of the biodegradability and toxicity. Environ. Pollut. 2016, 208, 467-476. [CrossRef] [PubMed]

3. Espinosa, E.; Zamora, P.; Feliu, J.; González Barón, M. Classification of anticancer drugs-A new system based on therapeutic targets. Cancer Treat. Rev. 2003, 29, 515-523. [CrossRef]

4. Kosjek, T.; Heath, E. Occurrence, fate and determination of cytostatic pharmaceuticals in the environment. Trends Anal. Chem. 2011, 30, 1065-1087. [CrossRef]

5. Meegan, M.J.; O’Boyle, N.M. Special Issue “Anticancer Drugs". Pharmaceuticals 2019, 12, 134. [CrossRef] [PubMed]

6. Siegel, R.L.; Miller, K.D.; Jemal, A. Cancer statistics, 2020. CA A Cancer J. Clin. 2020, 70, 7-30. [CrossRef] [PubMed]

7. Sun, J.; Wei, Q.; Zhou, Y.; Wang, J.; Liu, Q.; Xu, H. A systematic analysis of FDA-approved anticancer drugs. BMC Syst. Biol. 2017, 11, 87. [CrossRef] [PubMed]

8. Aitken, M. Global Oncology Trend Report: A Review of 2016 and Outlook to 2020. IMS Inst. Healthc. Inform. 2016, 1, 1-45.

9. Hoppe-Tichy, T. Current challenges in European oncology pharmacy practice. J. Oncol. Pharm. Pract. 2010, 16, 9-18. [CrossRef]

10. Salas-Vega, S.; Mossialos, E. Cancer Drugs Provide Positive Value In Nine Countries, But The United States Lags In Health Gains Per Dollar Spent. Health Aff. 2016, 35, 813-823. [CrossRef]

11. Heath, E.; Isidori, M.; Kosjek, T.; Filipič, M. Fate and Effects of Anticancer Drugs in the Environment, 1st ed.; Springer Nature: Cham, Switzerland, 2020. [CrossRef]

12. Bray, F.; Ferlay, J.; Soerjomataram, I.; Siegel, R.; Torre, L.; Jemal, A. Global Cancer Statistics 2018: GLOBOCAN estimates of incidence and mortality worldwide for 36 cancers in 185 countries. CA Cancer J. Clin. 2018, 68, 394-424. [CrossRef] [PubMed]

13. Hofmarcher, T.; Brådvik, G.; Svedman, C.; Lindgren, P.; Jönsson, B.; Wilking, N. Comparator Report on Cancer in Europe 2019-Disease Burden, Costs and Access to Medicines; IHE: Lund, Sweden, 2019.

14. EMA Drugs Approved in 2019. Available online: https://pharmaboardroom.com/facts/ema-drugs-approvedin-2019/ (accessed on 17 June 2020).

15. 2019 in Review: New Cancer Drug Approvals. Available online: https://www.cancer.org/latest-news/2019in-review-new-cancer-drug-approvals.html (accessed on 17 June 2020).

16. Chen, L.; Zeng, W.-M.; Cai, Y.-D.; Feng, K.-Y.; Chou, K.-C. Predicting Anatomical Therapeutic Chemical (ATC) Classification of Drugs by Integrating Chemical-Chemical Interactions and Similarities. PLoS ONE 2012, 7, e35254. [CrossRef] [PubMed]

17. Azuma, T. Distribution of Anticancer Drugs in River Waters and Sediments of the Yodo River Basin, Japan. Appl. Sci. 2018, 8, 2043. [CrossRef]

18. Booker, V.; Halsall, C.; Llewellyn, N.; Johnson, A.; Williams, R. Prioritising anticancer drugs for environmental monitoring and risk assessment purposes. Sci. Total Environ. 2014, 473-474, 159-170. [CrossRef]

19. Kümmerer, K.; Haiß, A.; Schuster, A.; Hein, A.; Ebert, I. Antineoplastic compounds in the environment-Substances of special concern. Environ. Sci. Pollut. Res. 2016, 23, 14791-14804. [CrossRef]

20. Heath, E.; Filipič, M.; Kosjek, T.; Isidori, M. Fate and effects of the residues of anticancer drugs in the environment. Environ. Sci. Pollut. Res. 2016, 23, 14687-14691. [CrossRef]

21. Zhang, J.; Chang, V.W.; Giannis, A.; Wang, J.Y. Removal of cytostatic drugs from aquatic environment: A review. Sci. Total Environ. 2013, 445-446, 281-298. [CrossRef] 
22. Toolaram, A.P.; Kummerer, K.; Schneider, M. Environmental risk assessment of anti-cancer drugs and their transformation products: A focus on their genotoxicity characterization-state of knowledge and short comings. Mutat. Res. Rev. Mutat. Res. 2014, 760, 18-35. [CrossRef]

23. Ribeiro, A.R.; Goncalves, V.M.; Maia, A.S.; Carvalho, M.F.; Castro, P.M.; Tiritan, M.E. Microbial degradation of pharmaceuticals followed by a simple HPLC-DAD method. J. Environ. Sci. Health Part AToxic/Hazard Subst. Environ. Eng. 2012, 47, 2151-2158. [CrossRef]

24. Murphy, C.D. Microbial degradation of fluorinated drugs: Biochemical pathways, impacts on the environment and potential applications. Appl. Microbiol. Biotechnol. 2016, 100, 2617-2627. [CrossRef]

25. Steger-Hartmann, T.; Kümmerer, K.; Hartmann, A. Biological Degradation of Cyclophosphamide and Its Occurrence in Sewage Water. Ecotoxicol. Environ. Saf. 1997, 36, 174-179. [CrossRef] [PubMed]

26. Kümmerer, K.; Al-Ahmad, A. Biodegradability of the Anti-tumour Agents 5-Fluorouracil, Cytarabine, and Gemcitabine: Impact of the Chemical Structure and Synergistic Toxicity with Hospital Effluent. Acta Hydrochim. Hydrobiol. 1997, 25, 166-172. [CrossRef]

27. Česen, M.; Kosjek, T.; Laimou-Geraniou, M.; Kompare, B.; Širok, B.; Lambropolou, D.; Heath, E. Occurrence of cyclophosphamide and ifosfamide in aqueous environment and their removal by biological and abiotic wastewater treatment processes. Sci. Total Environ. 2015, 527-528, 465-473. [CrossRef]

28. Bhalla, A.; Bischoff, K.M.; Sani, R.K. Highly Thermostable Xylanase Production from A Thermophilic Geobacillus sp. Strain WSUCF1 Utilizing Lignocellulosic Biomass. Front. Bioeng. Biotechnol. 2015, 3, 84:1-84:8. [CrossRef] [PubMed]

29. Goh, K.M.; Chan, K.-G.; Sani, R.K.; Donati, E.R.; Reysenbach, A.-L. Editorial: Genetics, Genomics and -Omics of Thermophiles. Front. Microbiol. 2017, 8, 560:1-560:2. [CrossRef]

30. Carlson, C.; Singh, N.K.; Bibra, M.; Sani, R.K.; Venkateswaran, K. Pervasiveness of UVC254-resistant Geobacillus strains in extreme environments. Appl. Microbiol. Biotechnol. 2018, 102, 1869-1887. [CrossRef]

31. Rathinam, N.K.; Tripathi, A.K.; Smirnova, A.; Beyenal, H.; Sani, R.K. Engineering rheology of electrolytes using agar for improving the performance of bioelectrochemical systems. Bioresour. Technol. 2018, 263, 242-249. [CrossRef]

32. David, A.; Govil, T.; Tripathi, A.; McGeary, J.; Farrar, K.; Sani, R. Thermophilic Anaerobic Digestion: Enhanced and Sustainable Methane Production from Co-Digestion of Food and Lignocellulosic Wastes. Energies 2018, 11, 2058. [CrossRef]

33. Tripathi, A.K.; Kumari, M.; Kumar, A.; Kumar, S. Generation of Biogas Using Pine Needles as Substrate in Domestic Biogas Plant. Int. J. Renew. Energy. Res. 2015, 5, 6.

34. David, A.; Tripathi, A.K.; Sani, R.K. Acetate Production from Cafeteria Wastes and Corn Stover Using a Thermophilic Anaerobic Consortium: A Prelude Study for the Use of Acetate for the Production of Value-Added Products. Microorganisms 2020, 8, 353. [CrossRef]

35. Beek, B.; Böhling, S.; Bruckmann, U.; Franke, C.; Jöhncke, U.; Studinger, G. The Assessment of Bioaccumulation; Springer: Berlin/Heidelberg, Germany, 2001; Volume 2.

36. Kuntworbe, N.; Alany, R.G.; Brimble, M.; Al-Kassas, R. Determination of pKa and forced degradation of the indoloquinoline antimalarial compound cryptolepine hydrochloride. Pharm. Dev. Technol. 2013, 18, 866-876. [CrossRef] [PubMed]

37. Azuma, T.; Ishiuchi, H.; Inoyama, T.; Teranishi, Y.; Yamaoka, M.; Sato, T.; Mino, Y. Occurrence and fate of selected anticancer, antimicrobial, and psychotropic pharmaceuticals in an urban river in a subcatchment of the Yodo River basin, Japan. Environ. Sci. Pollut. Res. Int. 2015, 22, 18676-18686. [CrossRef] [PubMed]

38. Folens, K.; Abebe, A.; Tang, J.; Ronsse, F.; Du Laing, G. Biosorption of residual cisplatin, carboplatin and oxaliplatin antineoplastic drugs in urine after chemotherapy treatment. Environ. Chem. 2018, 15, 506-512. [CrossRef]

39. Scheytt, T.; Mersmann, P.; Lindstadt, R.; Heberer, T. Determination of sorption coefficients of pharmaceutically active substances carbamazepine, diclofenac, and ibuprofen, in sandy sediments. Chemosphere 2005, 60, 245-253. [CrossRef] [PubMed]

40. Besse, J.P.; Latour, J.F.; Garric, J. Anticancer drugs in surface waters: What can we say about the occurrence and environmental significance of cytotoxic, cytostatic and endocrine therapy drugs? Environ. Int. 2012, 39, 73-86. [CrossRef] [PubMed] 
41. Buerge, I.J.; Buser, H.-R.; Poiger, T.; Müller, M.D. Occurrence and Fate of the Cytostatic Drugs Cyclophosphamide and Ifosfamide in Wastewater and Surface Waters. Environ. Sci. Technol. 2006, 40, 7242-7250. [CrossRef] [PubMed]

42. Aherne, G.W.; Hardcastle, A.; Nield, A.H. Cytotoxic drugs and the aquatic environment: Estimation of bleomycin in river and water samples. J. Pharm. Pharmacol. 1990, 42, 741-742. [CrossRef]

43. Jureczko, M.; Kalka, J. Cytostatic pharmaceuticals as water contaminants. Eur. J. Pharmacol. 2020, 866, 172816. [CrossRef]

44. Ghafuria, Y. Environmental risk assessment of platinum cytotoxic drugs: A focus on toxicity characterization of hospital effluents. Int. J. Environ. Sci. Technol. 2018, 15, 1983-1990. [CrossRef]

45. Richardson, M.L.; Bowron, J.M. The fate of pharmaceutical chemicals in the aquatic environment. J. Pharm. Pharm. 1985, 37, 1-12. [CrossRef]

46. Kümmerer, K. The presence of pharmaceuticals in the environment due to human use-present knowledge and future challenges. J. Environ. Manag. 2009, 90, 2354-2366. [CrossRef] [PubMed]

47. Ort, C.; Lawrence, M.G.; Reungoat, J.; Eaglesham, G.; Carter, S.; Keller, J. Determining the fraction of pharmaceutical residues in wastewater originating from a hospital. Water Res. 2010, 44, 605-615. [CrossRef] [PubMed]

48. Mahnik, S.N.; Lenz, K.; Weissenbacher, N.; Mader, R.M.; Fuerhacker, M. Fate of 5-fluorouracil, doxorubicin, epirubicin, and daunorubicin in hospital wastewater and their elimination by activated sludge and treatment in a membrane-bio-reactor system. Chemosphere 2007, 66, 30-37. [CrossRef]

49. Weissbrodt, D.; Kovalova, L.; Ort, C.; Pazhepurackel, V.; Moser, R.; Hollender, J.; Siegrist, H.; McArdell, C.S. Mass Flows of X-ray Contrast Media and Cytostatics in Hospital Wastewater. Environ. Sci. Technol. 2009, 43, 4810-4817. [CrossRef] [PubMed]

50. Judson, I.R.; Beale, P.J.; Trigo, J.M.; Aherne, W.; Crompton, T.; Jones, D.; Bush, E.; Reigner, B. A human capecitabine excretion balance and pharmacokinetic study after administration of a single oral dose of 14C-labelled drug. Investig. New Drugs 1999, 17, 49-56. [CrossRef] [PubMed]

51. Li, W.C. Occurrence, sources, and fate of pharmaceuticals in aquatic environment and soil. Environ. Pollut. 2014, 187, 193-201. [CrossRef]

52. Sui, Q.; Cao, X.; Lu, S.; Zhao, W.; Qiu, Z.; Yu, G. Occurrence, sources and fate of pharmaceuticals and personal care products in the groundwater: A review. Emerg. Contam. 2015, 1, 14-24. [CrossRef]

53. Souza, D.M.; Reichert, J.F.; Martins, A.F. A simultaneous determination of anti-cancer drugs in hospital effluent by DLLME HPLC-FLD, together with a risk assessment. Chemosphere 2018, 201, 178-188. [CrossRef]

54. Johnson Andrew, C.; Oldenkamp, R.; Dumont, E.; Sumpter John, P. Predicting concentrations of the cytostatic drugs cyclophosphamide, carboplatin, 5-fluorouracil, and capecitabine throughout the sewage effluents and surface waters of europe. Environ. Toxicol. Chem. 2013, 32, 1954-1961. [CrossRef]

55. Lee, D.; Choi, K. Comparison of regulatory frameworks of environmental risk assessments for human pharmaceuticals in EU, USA, and Canada. Sci. Total Environ. 2019, 671, 1026-1035. [CrossRef]

56. Dundas, C.M.; Graham, A.J.; Romanovicz, D.K.; Keitz, B.K. Extracellular Electron Transfer by Shewanella oneidensis Controls Palladium Nanoparticle Phenotype. ACS Synth. Biol. 2018, 7, 2726-2736. [CrossRef] [PubMed]

57. Rowney, N.C.; Johnson, A.C.; Williams, R.J. Erratum: Cytotoxic drugs in drinking water: A prediction and risk assessment exercise for the Thames catchment in the United Kingdom. Environ. Toxicol. Chem. 2011, 30, 1729. [CrossRef]

58. Kidd, K.A.; Blanchfield, P.J.; Mills, K.H.; Palace, V.P.; Evans, R.E.; Lazorchak, J.M.; Flick, R.W. Collapse of a fish population after exposure to a synthetic estrogen. Proc. Natl. Acad. Sci. USA 2007, 104, 8897-8901. [CrossRef] [PubMed]

59. Cristovao, M.B.; Janssens, R.; Yadav, A.; Pandey, S.; Luis, P.; Van der Bruggen, B.; Dubey, K.K.; Mandal, M.K.; Crespo, J.G.; Pereira, V.J. Predicted concentrations of anticancer drugs in the aquatic environment: What should we monitor and where should we treat? J. Hazard. Mater. 2020, 392, 122330. [CrossRef] [PubMed]

60. Ng, C.A.; Scheringer, M.; Fenner, K.; Hungerbuhler, K. A framework for evaluating the contribution of transformation products to chemical persistence in the environment. Environ. Sci. Technol. 2011, 45, 111-117. [CrossRef] [PubMed]

61. Escher, B.I.; Fenner, K. Recent Advances in Environmental Risk Assessment of Transformation Products. Environ. Sci. Technol. 2011, 45, 3835-3847. [CrossRef] [PubMed] 
62. Ventola, C.L. The antibiotic resistance crisis: Part 1: Causes and threats. Pharm. Ther. 2015, 40, $277-283$.

63. Davies, J.; Davies, D. Origins and Evolution of Antibiotic Resistance. Microbiol. Mol. Biol. Rev. 2010, 74, 417-433. [CrossRef]

64. Seruga Music, M.; Hrenovic, J.; Goic-Barisic, I.; Hunjak, B.; Skoric, D.; Ivankovic, T. Emission of extensively-drug-resistant Acinetobacter baumannii from hospital settings to the natural environment. J. Hosp. Infect. 2017, 96, 323-327. [CrossRef]

65. Economou, V.; Gousia, P. Agriculture and food animals as a source of antimicrobial-resistant bacteria. Infect. Drug Resist 2015, 8, 49-61. [CrossRef]

66. Ashraf, M.; Mustafa, B.-E.; Rehman, S.-U.; Bashir, M.K.; Ashraf, M.A. Emergence of Antimicrobial Resistance, Causes, Molecular Mechanisms, and Prevention Strategies: A Bovine Perspective. In Bovine Science-A Key to Sustainable Development; InTech Open: London, UK, 2019. [CrossRef]

67. Amadio, J.; Murphy, C.D. Production of human metabolites of the anti-cancer drug flutamide via biotransformation in Cunninghamella species. Biotechnol. Lett. 2011, 33, 321-326. [CrossRef] [PubMed]

68. Busi, S.; Swaraj Pattnaik, S. Chapter 9-Current Status and Applications of Actinobacteria in the Production of Anticancerous Compounds. In New and Future Developments in Microbial Biotechnology and Bioengineering; Singh, B.P., Gupta, V.K., Passari, A.K., Eds.; Elsevier: Amsterdam, The Netherlands, 2018; pp. 137-153. [CrossRef]

69. Cruz-Morato, C.; Ferrando-Climent, L.; Rodriguez-Mozaz, S.; Barcelo, D.; Marco-Urrea, E.; Vicent, T.; Sarra, M. Degradation of pharmaceuticals in non-sterile urban wastewater by Trametes versicolor in a fluidized bed bioreactor. Water Res. 2013, 47, 5200-5210. [CrossRef] [PubMed]

70. Ferrando-Climent, L.; Cruz-Morato, C.; Marco-Urrea, E.; Vicent, T.; Sarra, M.; Rodriguez-Mozaz, S.; Barcelo, D. Non conventional biological treatment based on Trametes versicolor for the elimination of recalcitrant anticancer drugs in hospital wastewater. Chemosphere 2015, 136, 9-19. [CrossRef]

71. Tadkaew, N.; Hai, F.I.; McDonald, J.A.; Khan, S.J.; Nghiem, L.D. Removal of trace organics by MBR treatment: The role of molecular properties. Water Res. 2011, 45, 2439-2451. [CrossRef] [PubMed]

72. Rodríguez-Rodríguez, C.E.; Jesús García-Galán, M.; Blánquez, P.; Díaz-Cruz, M.S.; Barceló, D.; Caminal, G.; Vicent, T. Continuous degradation of a mixture of sulfonamides by Trametes versicolor and identification of metabolites from sulfapyridine and sulfathiazole. J. Hazard. Mater. 2012, 213, 347-354. [CrossRef]

73. Casini, A.; Scozzafava, A.; Mastrolorenzo, A.; Supuran, L.T. Sulfonamides and sulfonylated derivatives as anticancer agents. Curr. Cancer.Drug Targets 2002, 2, 55-75. [CrossRef]

74. Bourbonnais, R.; Leech, D.; Paice, M.G. Electrochemical analysis of the interactions of laccase mediators with lignin model compounds. Biochim. Biophys. Acta. Gen. Subj. 1998, 1379, 381-390. [CrossRef]

75. Schwarz, J.; Aust, M.-O.; Thiele-Bruhn, S. Metabolites from fungal laccase-catalysed transformation of sulfonamides. Chemosphere 2010, 81, 1469-1476. [CrossRef]

76. Marco-Urrea, E.; Perez-Trujillo, M.; Blanquez, P.; Vicent, T.; Caminal, G. Biodegradation of the analgesic naproxen by Trametes versicolor and identification of intermediates using HPLC-DAD-MS and NMR. Bioresour. Technol. 2010, 101, 2159-2166. [CrossRef]

77. Thun, M.J.; Henley, S.J.; Patrono, C. Nonsteroidal Anti-inflammatory Drugs as Anticancer Agents: Mechanistic, Pharmacologic, and Clinical Issues. J. Natl. Cancer. Inst. 2002, 94, 252-266. [CrossRef]

78. Murphy, C.D.; Palmer-Brown, W.; Quinn, L.; Saccomanno, M. 7-Microbial metabolism of fluorinated drugs. In Fluorine in Life Sciences: Pharmaceuticals, Medicinal Diagnostics, and Agrochemicals; Haufe, G., Leroux, F.R., Eds.; Academic Press: Cambridge, MA, USA, 2019; pp. 281-299. [CrossRef]

79. Hidde Boersma, F.G.; Colin McRoberts, W.; Cobb, S.L.; Murphy, C.D. A 19F NMR study of fluorobenzoate biodegradation by Sphingomonas sp. HB-1. Fems. Microbiol. Lett. 2004, 237, 355-361. [CrossRef]

80. Kim, E.J.; Jeon, J.R.; Kim, Y.M.; Murugesan, K.; Chang, Y.S. Mineralization and transformation of monofluorophenols by Pseudonocardia benzenivorans. Appl. Microbiol. Biotechnol. 2010, 87, 1569-1577. [CrossRef] [PubMed]

81. Lutterbeck, C.A.; Wilde, M.L.; Baginska, E.; Leder, C.; Machado, E.L.; Kummerer, K. Degradation of 5-FU by means of advanced (photo)oxidation processes: $\mathrm{UV} / \mathrm{H}_{2} \mathrm{O}_{2}, \mathrm{UV} / \mathrm{Fe}^{2+} / \mathrm{H}_{2} \mathrm{O}_{2}$ and $\mathrm{UV} / \mathrm{TiO}_{2}-\mathrm{Comparison}$ of transformation products, ready biodegradability and toxicity. Sci. Total Environ. 2015, 527-528, 232-245. [CrossRef] [PubMed] 
82. Engesser, K.-H.; Rubio, M.A.; Knackmuss, H.-J. Bacterial metabolism of side-chain-fluorinated aromatics: Unproductive meta-cleavage of 3-trifluoromethylcatechol. Appl. Microbiol. Biotechnol. 1990, 32, 600-608. [CrossRef] [PubMed]

83. Westman, E.L.; Canova, M.J.; Radhi, I.J.; Koteva, K.; Kireeva, I.; Waglechner, N.; Wright, G.D. Bacterial Inactivation of the Anticancer Drug Doxorubicin. Chem. Biol. 2012, 19, 1255-1264. [CrossRef]

84. Pepper, I.L.; Gentry, T.J. Chapter 4-Earth Environments. In Environmental. Microbiology, 3rd ed.; Pepper, I.L., Gerba, C.P., Gentry, T.J., Eds.; Academic Press: San Diego, CA, USA, 2015; pp. 59-88. [CrossRef]

85. Friedrich, T.; Scheide, D. The respiratory complex I of bacteria, archaea and eukarya and its module common with membrane-bound multisubunit hydrogenases1. FEBS Lett. 2000, 479, 1-5. [CrossRef]

86. Geller, L.T.; Barzily-Rokni, M.; Danino, T.; Jonas, O.H.; Shental, N.; Nejman, D.; Gavert, N.; Zwang, Y.; Cooper, Z.A.; Shee, K.; et al. Potential role of intratumor bacteria in mediating tumor resistance to the chemotherapeutic drug gemcitabine. Science 2017, 357, 1156-1160. [CrossRef]

87. Radjenović, J.; Petrović, M.; Barceló, D. Fate and distribution of pharmaceuticals in wastewater and sewage sludge of the conventional activated sludge (CAS) and advanced membrane bioreactor (MBR) treatment. Water Res. 2009, 43, 831-841. [CrossRef]

88. Chang, H.; Wan, Y.; Wu, S.; Fan, Z.; Hu, J. Occurrence of androgens and progestogens in wastewater treatment plants and receiving river waters: Comparison to estrogens. Water Res. 2011, 45, 732-740. [CrossRef]

89. Fan, Z.; Wu, S.; Chang, H.; Hu, J. Behaviors of glucocorticoids, androgens and progestogens in a municipal sewage treatment plant: Comparison to estrogens. Environ. Sci. Technol. 2011, 45, 2725-2733. [CrossRef]

90. Ortiz de García, S.; Pinto Pinto, G.; García Encina, P.; Irusta Mata, R. Consumption and occurrence of pharmaceutical and personal care products in the aquatic environment in Spain. Sci. Total Environ. 2013, 444, 451-465. [CrossRef]

91. Gómez-Canela, C.; Santos, M.S.F.; Franquet-Griell, H.; Alves, A.; Ventura, F.; Lacorte, S. Predicted Environmental Concentrations: A Useful Tool to Evaluate the Presence of Cytostatics in Surface Waters. In Fate and Effects of Anticancer Drugs in the Environment; Heath, E., Isidori, M., Kosjek, T., Filipič, M., Eds.; Springer International Publishing: Cham, Switzerland, 2020; pp. 27-54. [CrossRef]

92. Aukema, K.G.; Escalante, D.E.; Maltby, M.M.; Bera, A.K.; Aksan, A.; Wackett, L.P. In Silico Identification of Bioremediation Potential: Carbamazepine and Other Recalcitrant Personal Care Products. Environ. Sci. Technol. 2017, 51, 880-888. [CrossRef] [PubMed]

93. Ioannou-Ttofa, L.; Fatta-Kassinos, D. Cytostatic Drug Residues in Wastewater Treatment Plants: Sources, Removal Efficiencies and Current Challenges. In Fate and Effects of. Anticancer Drugs in the Environment; Heath, E., Isidori, M., Kosjek, T., Filipič, M., Eds.; Springer International Publishing: Cham, Switzerland, 2020; pp. 103-138. [CrossRef]

94. Chu, C.S.; Rubin, S.C. 17-Basic Principles of Chemotherapy. In Clinical Gynecologic Oncology, 9th ed.; DiSaia, P.J., Creasman, W.T., Mannel, R.S., McMeekin, D.S., Mutch, D.G., Eds.; Elsevier: Amsterdam, The Netherlands, 2018; pp. 449-469. [CrossRef]

95. Ferrando-Climent, L.; Rodriguez-Mozaz, S.; Barcelo, D. Development of a UPLC-MS/MS method for the determination of ten anticancer drugs in hospital and urban wastewaters, and its application for the screening of human metabolites assisted by information-dependent acquisition tool (IDA) in sewage samples. Anal. Bioanal. Chem. 2013, 405, 5937-5952. [CrossRef]

96. Negreira, N.; de Alda, M.L.; Barcelo, D. Cytostatic drugs and metabolites in municipal and hospital wastewaters in Spain: Filtration, occurrence, and environmental risk. Sci. Total Environ. 2014, 497-498, 68-77. [CrossRef] [PubMed]

97. Rabii, F.W.; Segura, P.A.; Fayad, P.B.; Sauve, S. Determination of six chemotherapeutic agents in municipal wastewater using online solid-phase extraction coupled to liquid chromatography-tandem mass spectrometry. Sci. Total Environ. 2014, 487, 792-800. [CrossRef] [PubMed]

98. Isidori, M.; Lavorgna, M.; Russo, C.; Kundi, M.; Zegura, B.; Novak, M.; Filipic, M.; Misik, M.; Knasmueller, S.; de Alda, M.L.; et al. Chemical and toxicological characterisation of anticancer drugs in hospital and municipal wastewaters from Slovenia and Spain. Environ. Pollut. 2016, 219, 275-287. [CrossRef] [PubMed]

99. Yin, J.; Shao, B.; Zhang, J.; Li, K. A preliminary study on the occurrence of cytostatic drugs in hospital effluents in Beijing, China. Bull. Environ. Contam. Toxicol. 2010, 84, 39-45. [CrossRef] 
100. Thomas, K.V.; Dye, C.; Schlabach, M.; Langford, K.H. Source to sink tracking of selected human pharmaceuticals from two Oslo city hospitals and a wastewater treatment works. J. Environ. Monit. 2007, 9, 1410-1418. [CrossRef]

101. Michael, C.; Bayona, J.M.; Lambropoulou, D.; Aguera, A.; Fatta-Kassinos, D. Two important limitations relating to the spiking of environmental samples with contaminants of emerging concern: How close to the real analyte concentrations are the reported recovered values? Environ. Sci. Pollut. Res. Int. 2017, 24, 15202-15205. [CrossRef]

102. Freres, P.; Jerusalem, G.; Moonen, M. Chapter 2-Categories of Anticancer Treatments. In Anti-Cancer Treatments and Cardiotoxicity; Lancellotti, P., Zamorano Gómez, J.L., Galderisi, M., Eds.; Academic Press: Boston, MA, USA, 2017; pp. 7-11. [CrossRef]

103. Kiffmeyer, T.; Götze, H.-J.; Jursch, M.; Lüders, U. Trace enrichment, chromatographic separation and biodegradation of cytostatic compounds in surface water. Fresenius J. Anal. Chem. 1998, 361, 185-191. [CrossRef]

104. Rosano, T.G. Ellenhorn's Medical Toxicology: Diagnosis and Treatment of Human Poisoning. Clin. Chem. 1998, 44, 366. [CrossRef]

105. Kosjek, T.; Perko, S.; Zigon, D.; Heath, E. Fluorouracil in the environment: Analysis, occurrence, degradation and transformation. J. Chromatogr. A 2013, 1290, 62-72. [CrossRef] [PubMed]

106. Yu, J.T.; Bouwer, E.J.; Coelhan, M. Occurrence and biodegradability studies of selected pharmaceuticals and personal care products in sewage effluent. Agric. Water. Manag. 2006, 86, 72-80. [CrossRef]

107. Straub, J.O. Combined environmental risk assessment for 5-fluorouracil and capecitabine in Europe. Integr. Environ. Assess Manag. 2010, 6, 540-566. [CrossRef] [PubMed]

108. Lutterbeck, C.A.; Baginska, E.; Machado, E.L.; Kummerer, K. Removal of the anti-cancer drug methotrexate from water by advanced oxidation processes: Aerobic biodegradation and toxicity studies after treatment. Chemosphere 2015, 141, 290-296. [CrossRef] [PubMed]

109. Martin, J.; Camacho-Munoz, D.; Santos, J.L.; Aparicio, I.; Alonso, E. Simultaneous determination of a selected group of cytostatic drugs in water using high-performance liquid chromatography-triple-quadrupole mass spectrometry. J. Sep. Sci. 2011, 34, 3166-3177. [CrossRef] [PubMed]

110. Martín, J.; Camacho-Muñoz, D.; Santos, J.L.; Aparicio, I.; Alonso, E. Occurrence and Ecotoxicological Risk Assessment of 14 Cytostatic Drugs in Wastewater. Water Air Soil Pollut. 2014, 225, 1896. [CrossRef]

111. Kosjek, T.; Negreira, N.; de Alda, M.L.; Barcelo, D. Aerobic activated sludge transformation of methotrexate: Identification of biotransformation products. Chemosphere 2015, 119, S42-S50. [CrossRef]

112. Ferrando-Climent, L.; Rodriguez-Mozaz, S.; Barcelo, D. Incidence of anticancer drugs in an aquatic urban system: From hospital effluents through urban wastewater to natural environment. Environ. Pollut. 2014, 193, 216-223. [CrossRef]

113. Pietsch, J.; Gunther, J.; Henle, T.; Dressler, J. Simultaneous determination of thirteen plant alkaloids in a human specimen by SPE and HPLC. J. Sep. Sci. 2008, 31, 2410-2416. [CrossRef]

114. Kosjek, T.; Negreira, N.; Heath, E.; López de Alda, M.; Barceló, D. Aerobic activated sludge transformation of vincristine and identification of the transformation products. Sci. Total Environ. 2018, 610-611, 892-904. [CrossRef] [PubMed]

115. Jeswani, G.; Paul, S.D. Chapter 15-Recent Advances in the Delivery of Chemotherapeutic Agents. In Nano-and Microscale Drug Delivery Systems; Grumezescu, A.M., Ed.; Elsevier: Amsterdam, The Netherlands, 2017; pp. 281-298. [CrossRef]

116. Wang, X.; Liu, W.; Xin, C.; Zheng, Y.; Cheng, Y.; Sun, S.; Li, R.; Zhu, X.-G.; Dai, S.Y.; Rentzepis, P.M.; et al. Enhanced limonene production in cyanobacteria reveals photosynthesis limitations. Proc. Natl. Acad. Sci. USA 2016, 113, 14225. [CrossRef] [PubMed]

117. Franquet-Griell, H.; Medina, A.; Sans, C.; Lacorte, S. Biological and photochemical degradation of cytostatic drugs under laboratory conditions. J. Hazard. Mater. 2017, 323, 319-328. [CrossRef] [PubMed]

118. Roberts, P.H.; Thomas, K.V. The occurrence of selected pharmaceuticals in wastewater effluent and surface waters of the lower Tyne catchment. Sci. Total Environ. 2006, 356, 143-153. [CrossRef]

119. Gómez-Canela, C.; Ventura, F.; Caixach, J.; Lacorte, S. Occurrence of cytostatic compounds in hospital effluents and wastewaters, determined by liquid chromatography coupled to high-resolution mass spectrometry. Anal. Bioanal. Chem. 2014, 406, 3801-3814. [CrossRef] [PubMed] 
120. Melin, T.; Jefferson, B.; Bixio, D.; Thoeye, C.; De Wilde, W.; De Koning, J.; van der Graaf, J.; Wintgens, T. Membrane bioreactor technology for wastewater treatment and reuse. Desalination 2006, 187, 271-282. [CrossRef]

121. Gu, Y.; Huang, J.; Zeng, G.; Shi, L.; Shi, Y.; Yi, K. Fate of pharmaceuticals during membrane bioreactor treatment: Status and perspectives. Bioresour. Technol. 2018, 268, 733-748. [CrossRef]

122. Lenz, K.; Mahnik, S.N.; Weissenbacher, N.; Mader, R.M.; Krenn, P.; Hann, S.; Koellensperger, G.; Uhl, M.; Knasmuller, S.; Ferk, F.; et al. Monitoring, removal and risk assessment of cytostatic drugs in hospital wastewater. Water Sci. Technol. J. Int. Assoc. Water Pollut. Res. 2007, 56, 141-149. [CrossRef]

123. Delgado, L.F.; Dorandeu, C.; Marion, B.; Gonzalez, C.; Faucet-Marquis, V.; Schetrite, S.; Albasi, C. Removal of a cytostatic drug by a membrane bioreactor. Desalin. Water Treat. 2009, 9, 112-118. [CrossRef]

124. Delgado, L.F.; Faucet-Marquis, V.; Pfohl-Leszkowicz, A.; Dorandeu, C.; Marion, B.; Schetrite, S.; Albasi, C. Cytotoxicity micropollutant removal in a crossflow membrane bioreactor. Bioresour. Technol. 2011, 102, 4395-4401. [CrossRef]

125. Kovalova, L.; Siegrist, H.; Singer, H.; Wittmer, A.; McArdell, C.S. Hospital wastewater treatment by membrane bioreactor: Performance and efficiency for organic micropollutant elimination. Environ. Sci. Technol. 2012, 46, 1536-1545. [CrossRef]

126. Avella, A.C.; Delgado, L.F.; Görner, T.; Albasi, C.; Galmiche, M.; de Donato, P. Effect of cytostatic drug presence on extracellular polymeric substances formation in municipal wastewater treated by membrane bioreactor. Bioresour. Technol. 2010, 101, 518-526. [CrossRef]

127. Meng, F.; Chae, S.-R.; Drews, A.; Kraume, M.; Shin, H.-S.; Yang, F. Recent advances in membrane bioreactors (MBRs): Membrane fouling and membrane material. Water Res. 2009, 43, 1489-1512. [CrossRef]

128. Wang, X.; Zhang, J.; Chang, V.W.C.; She, Q.; Tang, C.Y. Removal of cytostatic drugs from wastewater by an anaerobic osmotic membrane bioreactor. Chem. Eng. J. 2018, 339, 153-161. [CrossRef]

129. Gu, Y.; Chen, L.; Ng, J.-W.; Lee, C.; Chang, V.W.C.; Tang, C.Y. Development of anaerobic osmotic membrane bioreactor for low-strength wastewater treatment at mesophilic condition. J. Membr. Sci. 2015, 490, 197-208. [CrossRef]

130. Chang, H.-M.; Sun, Y.-C.; Chien, I.C.; Chang, W.-S.; Ray, S.S.; Cao, D.T.N.; Cong Duong, C.; Chen, S.-S. Innovative upflow anaerobic sludge osmotic membrane bioreactor for wastewater treatment. Bioresour. Technol. 2019, 287, 121466. [CrossRef] [PubMed]

131. Wu, Y.; Wang, X.; Tay, M.Q.X.; Oh, S.; Yang, L.; Tang, C.; Cao, B. Metagenomic insights into the influence of salinity and cytostatic drugs on the composition and functional genes of microbial community in forward osmosis anaerobic membrane bioreactors. Chem. Eng. J. 2017, 326, 462-469. [CrossRef]

132. Kovalova, L.; McArdell, C.S.; Hollender, J. Challenge of high polarity and low concentrations in analysis of cytostatics and metabolites in wastewater by hydrophilic interaction chromatography/tandem mass spectrometry. J. Chromatogr. A 2009, 1216, 1100-1108. [CrossRef] [PubMed]

133. Halling-Sorensen, B.; Nors Nielsen, S.; Lanzky, P.F.; Ingerslev, F.; Holten Lutzhoft, H.C.; Jorgensen, S.E. Occurrence, fate and effects of pharmaceutical substances in the environment-a review. Chemosphere 1998, 36, 357-393. [CrossRef]

134. Hamon, P.; Moulin, P.; Ercolei, L.; Marrot, B. Oncological ward wastewater treatment by membrane bioreactor: Acclimation feasibility and pharmaceuticals removal performances. J. Water Process Eng. 2018, 21, 9-26. [CrossRef]

135. Wang, X.-H.; Lin, A.Y.-C. Is the phototransformation of pharmaceuticals a natural purification process that decreases ecological and human health risks? Environ. Pollut. 2014, 186, 203-215. [CrossRef]

136. Badia-Fabregat, M.; Oller, I.; Malato, S. Overview on Pilot-Scale Treatments and New and Innovative Technologies for Hospital Effluent. In Hospital Wastewaters: Characteristics, Management, Treatment and Environmental Risks; Verlicchi, P., Ed.; Springer International Publishing: Cham, Switzerland, 2018; pp. $209-230$. [CrossRef]

137. Seira, J.; Sablayrolles, C.; Montréjaud-Vignoles, M.; Albasi, C.; Joannis-Cassan, C. Elimination of an anticancer drug (cyclophosphamide) by a membrane bioreactor: Comprehensive study of mechanisms. Biochem. Eng. J. 2016, 114, 155-163. [CrossRef]

138. Chen, Z.; Park, G.; Herckes, P.; Westerhoff, P. Physicochemical Treatment of Three Chemotherapy Drugs: Irinotecan, Tamoxifen, and Cyclophosphamide. J. Adv. Oxid. Technol. 2008, 11, 254-260. [CrossRef] 
139. Paci, A.; Martens, T.; Royer, J. Anodic oxidation of ifosfamide and cyclophosphamide: A biomimetic metabolism model of the oxazaphosphorinane anticancer drugs. Bioorg. Med. Chem. Lett. 2001, 11, 1347-1349. [CrossRef]

140. Oh, B.S.; Oh, S.; Kim, S.-J.; Choi, Y.; Hwang, T.-M. Optimization of wastewater reclamation and reuse system using membrane filtration and oxidation processes: Removal of pharmaceuticals. Desalin. Water Treat. 2016, 57, 10146-10151. [CrossRef]

141. Shojaee Nasirabadi, P.; Saljoughi, E.; Mousavi, S.M. Membrane processes used for removal of pharmaceuticals, hormones, endocrine disruptors and their metabolites from wastewaters: A review. Desalin. Water Treat. 2016, 57, 24146-24175. [CrossRef]

142. Dolar, D.; Košutić, K. Chapter 10-Removal of Pharmaceuticals by Ultrafiltration (UF), Nanofiltration (NF), and Reverse Osmosis (RO). In Comprehensive Analytical Chemistry; Petrovic, M., Barcelo, D., Pérez, S., Eds.; Elsevier: Amsterdam, The Netherlands, 2013; Volume 62, pp. 319-344.

143. Kimura, K.; Amy, G.; Drewes, J.E.; Heberer, T.; Kim, T.-U.; Watanabe, Y. Rejection of organic micropollutants (disinfection by-products, endocrine disrupting compounds, and pharmaceutically active compounds) by NF/RO membranes. J. Membr. Sci. 2003, 227, 113-121. [CrossRef]

144. Pronk, W.; Biebow, M.; Boller, M. Electrodialysis for Recovering Salts from a Urine Solution Containing Micropollutants. Environ. Sci. Technol. 2006, 40, 2414-2420. [CrossRef]

145. Wang, L.; Albasi, C.; Faucet-Marquis, V.; Pfohl-Leszkowicz, A.; Dorandeu, C.; Marion, B.; Causserand, C. Cyclophosphamide removal from water by nanofiltration and reverse osmosis membrane. Water Res. 2009, 43, 4115-4122. [CrossRef]

146. Escher, B.I.; Pronk, W.; Suter, M.J.F.; Maurer, M. Monitoring the Removal Efficiency of Pharmaceuticals and Hormones in Different Treatment Processes of Source-Separated Urine with Bioassays. Environ. Sci. Technol. 2006, 40, 5095-5101. [CrossRef]

147. Benvenuto, J.A.; Connor, T.H.; Monteith, D.K.; Laidlaw, J.L.; Adams, S.C.; Matney, T.S.; Theiss, J.C. Degradation and Inactivation of Antitumor Drugs. J. Pharm. Sci. 1993, 82, 988-991. [CrossRef] [PubMed]

148. Castegnaro, M.; Sportouch, M.H.; De Meo, M.; Laget, M.; Michelon, J.; Garren, L.; Hansel, S. Chemical degradation of wastes of antineoplastic agents 2-Six Anthracyclines: Idarubicin, doxorubicin, epirubicin, pirarubicin, aclarubicin, and daunorubicin. Int. Arch. Occup. Environ. Health 1997, 70, 378-384. [CrossRef] [PubMed]

149. Hansel, S.; Castegnaro, M.; Sportouch, M.H.; De Meo, M.; Milhavet, J.C.; Laget, M.; Dumenil, G. Chemical degradation of wastes of antineoplastic agents: Cyclophosphamide, ifosfamide, and melphalan. Int. Arch. Occup. Environ. Health. 1997, 69, 109-114. [CrossRef] [PubMed]

150. Lunn, G.; Sansone, E.B.; Andrews, A.W.; Hellwig, L.C. Degradation and disposal of some antineoplastic drugs. J. Pharm. Sci. 1989, 78, 652-659. [CrossRef]

151. Macholz, R. Laboratory decontamination and destruction of carcinogens in laboratory wastes: Some antineoplastic agents. International Agency for Research on Cancer. IARC Sci. Publ. 1985, 32, 1-634.

152. Martignac, M.; Balayssac, S.; Gilard, V.; Benoit-Marquié, F. Photochemical Degradation of the Anticancer Drug Bortezomib by V-UV/UV (185/254 nm) Investigated by 1H NMR Fingerprinting: A Way to Follow Aromaticity Evolution. J. Phys. Chem. A 2015, 119, 6215-6222. [CrossRef]

153. Lin, A.Y.-C.; Wang, X.-H.; Lee, W.-N. Phototransformation Determines the Fate of 5-Fluorouracil and Cyclophosphamide in Natural Surface Waters. Environ. Sci. Technol. 2013, 47, 4104-4112. [CrossRef]

154. Trawiński, J.; Skibiński, R. Studies on photodegradation process of psychotropic drugs: A review. Environ. Sci. Pollut. Res. Int. 2017, 24, 1152-1199. [CrossRef]

155. Gómez-Canela, C.; Bolivar-Subirats, G.; Tauler, R.; Lacorte, S. Powerful combination of analytical and chemometric methods for the photodegradation of 5-Fluorouracil. J. Pharm. Biomed. Anal. 2017, 137, $33-41$. [CrossRef] [PubMed]

156. Ganzenko, O.; Oturan, N.; Sirés, I.; Huguenot, D.; van Hullebusch, E.D.; Esposito, G.; Oturan, M.A. Fast and complete removal of the 5 -fluorouracil drug from water by electro-Fenton oxidation. Environ. Chem. Lett. 2018, 16, 281-286. [CrossRef]

157. Koltsakidou, A.; Antonopoulou, M.; Sykiotou, M.; Evgenidou, E.; Konstantinou, I.; Lambropoulou, D.A. Photo-Fenton and Fenton-like processes for the treatment of the antineoplastic drug 5-fluorouracil under simulated solar radiation. Environ. Sci. Pollut. Res. 2017, 24, 4791-4800. [CrossRef] [PubMed] 
158. Anheden, M.; Goswami, D.Y.; Svedberg, G. Photocatalytic Treatment of Wastewater From 5-Fluorouracil Manufacturing. J. Solar Energy Eng. 1996, 118, 2-8. [CrossRef]

159. Burleson, G.R.; Chambers, T.M. Effect of ozonation on the mutagenicity of carcinogens in aqueous solution. Environ. Mutagenesis 1982, 4, 469-476. [CrossRef] [PubMed]

160. Gouider, M.; Mlaik, N.; Feki, M.; Sayadi, S. Integrated physicochemical and biological treatment process for fluoride and phosphorus removal from fertilizer plant wastewater. Water Environ. Res. 2011, 83, 731-738. [CrossRef] [PubMed]

161. Feng, F.; Xu, Z.; Li, X.; You, W.; Zhen, Y. Advanced treatment of dyeing wastewater towards reuse by the combined Fenton oxidation and membrane bioreactor process. J. Environ. Sci. 2010, 22, 1657-1665. [CrossRef]

162. Calza, P.; Medana, C.; Sarro, M.; Rosato, V.; Aigotti, R.; Baiocchi, C.; Minero, C. Photocatalytic degradation of selected anticancer drugs and identification of their transformation products in water by liquid chromatography-high resolution mass spectrometry. J. Chromatogr. A 2014, 1362, 135-144. [CrossRef] [PubMed]

163. Lin, A.Y.; Hsueh, J.H.; Hong, P.K. Removal of antineoplastic drugs cyclophosphamide, ifosfamide, and 5-fluorouracil and a vasodilator drug pentoxifylline from wastewaters by ozonation. Environ. Sci. Pollut. Res. Int. 2015, 22, 508-515. [CrossRef] [PubMed]

164. Negreira, N.; Regueiro, J.; Lopez de Alda, M.; Barcelo, D. Degradation of the anticancer drug erlotinib during water chlorination: Non-targeted approach for the identi fi cation of transformation products. Water Res. 2015, 85, 103-113. [CrossRef]

165. Huo, Z.; Wang, S.; Shao, H.; Wang, H.; Xu, G. Radiolytic degradation of anticancer drug capecitabine in aqueous solution: Kinetics, reaction mechanism, and toxicity evaluation. Environ. Sci. Pollut. Res. 2020. [CrossRef]

166. Barış̧̧ı, S.; Turkay, O.; Ulusoy, E.; Şeker, M.G.; Yüksel, E.; Dimoglo, A. Electro-oxidation of cytostatic drugs: Experimental and theoretical identification of by-products and evaluation of ecotoxicological effects. Chem. Eng. J. 2018, 334, 1820-1827. [CrossRef]

167. Governo, M.; Santos, M.S.F.; Alves, A.; Madeira, L.M. Degradation of the cytostatic 5-Fluorouracil in water by Fenton and photo-assisted oxidation processes. Environ. Sci. Pollut. Res. 2017, 24, 844-854. [CrossRef]

168. Koltsakidou, A.; Antonopoulou, M.; Evgenidou, E.; Konstantinou, I.; Lambropoulou, D.A. Cytarabine degradation by simulated solar assisted photocatalysis using $\mathrm{TiO}_{2}$. Chem. Eng. J. 2017, 316, 823-831. [CrossRef]

169. Janssens, R.; Cristóvão, B.M.; Bronze, M.R.; Crespo, J.G.; Pereira, V.J.; Luis, P. Photocatalysis Using UV-A and UV-C Light Sources for Advanced Oxidation of Anti-Cancer Drugs Spiked in Laboratory-Grade Water and Synthetic Urine. Ind. Eng. Chem. Res. 2020, 59, 647-653. [CrossRef]

170. Collivignarelli, M.C.; Abbà, A.; Bertanza, G.; Setti, M.; Barbieri, G.; Frattarola, A. Integrating novel (thermophilic aerobic membrane reactor-TAMR) and conventional (conventional activated sludge-CAS) biological processes for the treatment of high strength aqueous wastes. Bioresour. Technol. 2018, 255, 213-219. [CrossRef] [PubMed]

171. Kårelid, V.; Larsson, G.; Björlenius, B. Pilot-scale removal of pharmaceuticals in municipal wastewater: Comparison of granular and powdered activated carbon treatment at three wastewater treatment plants. J. Environ. Manag. 2017, 193, 491-502. [CrossRef]

172. Lienert, J.B.; Bürki, T.; Escher, B.I. Reducing micropollutants with source control: Substance flow analysis of 212 pharmaceuticals in faeces and urine. Water Sci. Technol. 2007, 56, 87-96. [CrossRef] [PubMed]

173. Wilsenach, J.A.; Van Loosdrecht, M.C.M. Effects of Separate Urine Collection on Advanced Nutrient Removal Processes. Environ. Sci. Technol. 2004, 38, 1208-1215. [CrossRef]

174. Wilsenach, J.; van Loosdrecht, M. Impact of separate urine collection on wastewater treatment systems. Water Sci. Technol. J. Int. Assoc. Water Pollut. Res. 2003, 48, 103-110. [CrossRef]

175. Collivignarelli, M.C.; Abba, A.; Bertanza, G. Treatment of high strength pharmaceutical wastewaters in a Thermophilic Aerobic Membrane Reactor (TAMR). Water Res. 2014, 63, 190-198. [CrossRef] [PubMed]

176. Duncan, J.; Bokhary, A.; Fatehi, P.; Kong, F.; Lin, H.; Liao, B. Thermophilic membrane bioreactors: A review. Bioresour. Technol. 2017, 243, 1180-1193. [CrossRef]

177. Barisci, S.; Turkay, O.; Ulusoy, E.; Soydemir, G.; Seker, M.G.; Dimoglo, A. Electrochemical treatment of anti-cancer drug carboplatin on mixed-metal oxides and boron doped diamond electrodes: Density functional theory modelling and toxicity evaluation. J. Hazard. Mater. 2017, 344, 316-321. [CrossRef] [PubMed] 
178. Zhang, Y.; Yu, T.; Han, W.; Sun, X.; Li, J.; Shen, J.; Wang, L. Electrochemical treatment of anticancer drugs wastewater containing 5-Fluoro-2-Methoxypyrimidine using a tubular porous electrode electrocatalytic reactor. Electrochim. Acta. 2016, 220, 211-221. [CrossRef]

179. Manson, M.M. Epoxides-Is there a human health problem? Br. J. Ind. Med. 1980, 37, 317-336. [CrossRef] 